\title{
La selección temática de la crítica de vinos en la prensa española
}

\author{
José Ignacio Armentia, José María Caminos \\ Catedráticos de Periodismo en la UPV-EHU \\ Flora Marín \\ Profesora titular de Comunicación Audiovisual y Publicidad en la UPV-EHU
}

\begin{abstract}
Resumen
La crítica enológica, tal y como sucede con otro tipo de críticas de consumo, no ha llegado todavía a las secciones diarias de los periódicos españoles, quedando su presencia restringida a suplementos temáticos y de fin de semana. La morfología de estos textos es muy variada. Algunos responden al modelo clásico de la crítica, mientras que otros estarían más cercanos a la reseña valorativa. La selección temática también varía mucho de unas publicaciones a otras, con una tendencia a primar los vinos de la zona cercana a la ubicación de la empresa editora.
\end{abstract}

\begin{abstract}
The enologic criticism, as it is happening to another variety of consumption criticism, has still not arrived at the daily sections of Spanish newspapers, being left its presence restricted to thematic supplements and weekend magazins. The morphology of these texts is very different among them. Some of them remember the classic model of the critic, whereas others would be nearer the opinion review. The thematic election also is very different from some publications to others, with a tendency to prioritize wines of the zone near the location of the publishing company.
\end{abstract}

Palabras clave: Crítica enológica, crítica de vino, periodismo de servicio.

Key words: Enologic criticism, wine criticism, service journalism.

\section{LA SELECCIÓN TEMÁtICA DE LA CRÍTICA DE VINOS EN LA PRENSA ESPAÑOLA}

\section{Suplementos temáticos y semanales}

- I presente artículo se basa en una investigación financiada por la UPV-EHU que lleva el título genérico de "La mitificación del vino a través de la crítica periodística: La crítica de consumo como nuevo subgénero periodístico".

Para su elaboración se han analizado todas las críticas relativas al vino publicadas durante 2003 en el suplemento El Viajero (38) de El País, en El Semanal (49) del Grupo Vocento, en el Magazine (22) de los Grupos Godó y Prensa Ibérica, y en el Dominical (46) del Grupo Zeta. En total se han estudiado 155 textos de los críticos Carlos Delgado (El País), Juan Luis Recio (El Semanal), Alfred Rexach (Magazine) y Quim Gil (Dominical). 
A diferencia de otras modalidades de la crítica (cinematográfica, teatral, etc.) que se han instalado definitivamente en la paginación normal de los periódicos, la mayor parte de las denominadas críticas de consumo siguen teniendo en los cuadernillos temáticos y en los suplementos arrevistados del fin de semana su ubicación habitual. La crítica sobre ordenadores, coches, hoteles, etc. por su carácter más especializado, raramente se nos ofrece dentro del alzado convencional (por ejemplo en la sección de Sociedad o similares). La proliferación de cuadernillos temáticos que se generaliza en la prensa española desde el inicio de la década de los 90 hace que este tipo de productos se convierta en el alojamiento de estas críticas sobre productos de consumo más o menos masivos.

De todos estos suplementos, los que inicialmente fueron más prolijos a la hora de dedicar secciones comentadas al consumo fueron las revistas del fin de semana; los ya populares dominicales. En algunos casos, los semanales han servido de trampolín de determinadas variantes de la crítica hacia otros cuadernillos más especializados. Este ha sido el caso de los textos de motor, que en la mayor parte de los grandes diarios cuenta con un suplemento total o parcialmente específico. También ha sido el caso de la informática y, en ciertos medios, de los viajes.

En el caso de la crítica enológica esta migración desde los dominicales en papel cuché y formato arrevistado hacia otros cuadernillos temáticos tan sólo se ha producido de forma excepcional, como ocurre con El País. Dicha publicación incluyó durante más de una década la sección "Beber" de Carlos Delgado dedicada a la crítica vinícola dentro del dominical El País Semanal. En octubre de 1999 esta publicación era rediseñada y entre los cambios más llamativos figuraba la desaparición de los textos del crítico Carlos Delgado que pasaron a ser incluidos en un cuadernillo de reciente creación denominado "El Viajero", editado los domingos y dedicado en un primer momento a informaciones y reportajes sobre viajes y motor. Desde la fecha citada "El Viajero" pasa a contar con una sección de hostelería y gastronomía, denominada "La buena vida", en el que se incluyen críticas sobre restaurantes, hoteles y vinos (en este último caso, bajo el cintillo de "Beber", manteniendo la misma denominación que se utilizaba en El País Semanal).

En mayo de 2001, "El Viajero" pasó a publicarse los sábados, junto con el suplemento cultural "Babelia". A pesar de sufrir un ligero rediseño, la sección "La buena vida", con su subapartado "Beber" se mantuvo prácticamente inalterable. Durante el período en el que se basó el análisis de la presente investigación (enero a diciembre de 2003) El País alcanzó una difusión media, según la OJD, de 440.226 ejemplares (si bien los domingos dicha cifra llegó a las 787.656 copias), lo que le situó como la publicación diaria más vendida del Estado.

Pero, como ya se ha mencionado, El País constituye una excepción en lo que a la ubicación de su crítica enológica se refiere. La inmensa mayoría de la prensa española incluye dicha variante periodística, dentro de los dominicales. Estas revistas suelen ser habitualmente distribuidas por diferentes diarios, bien de una misma cadena, o bien de otro tipo de propiedad, tras alcanzar acuerdos para 
compartir dicho producto. Algunos rotativos como el ya citado El País, El Mundo y otros de difusión más restringida, como Gara, distribuyen en exclusiva su propio dominical.

La estructura y morfología de estos suplementos de fin de semana suele ser muy similar en todos los casos. Salvo El Mundo, emplean un formato arrevistado, con papel couché y color en todas sus páginas. Sus contenidos se basan en algún reportaje en profundidad, alguna entrevista con un personaje conocido, una serie de artículos de opinión de colaboradores fijos, algunas tiras cómicas y diversas secciones dedicadas al consumo o a los servicios: moda, gastronomía, viajes, belleza, gimnasia y puesta a punto, salud, coches, etc. Es en este bloque de los servicios y el consumo donde se suele ubicar la información o la crítica de vinos.

\begin{tabular}{|c|c|c|}
\hline Suplemento & Diarios que los distribuyen & Difusión en 2003 \\
\hline El Semanal & $\begin{array}{l}\text { GRUPO VOCENTO y otros diarios } \\
\text { regionales y provinciales } \\
\text { (Heraldo de Aragón, La Voz de Galicia, } \\
\text { Diario de Mallorca, etc.) }\end{array}$ & 1.214 .692 \\
\hline \multirow[t]{2}{*}{ Magazine } & La Vanguardia, La Razón, & 785.810 \\
\hline & Grupo Prensa Ibérica & \\
\hline $\begin{array}{l}\text { El País Semanal } \\
\text { (desde octubre de } \\
1999 \text { la crítica de } \\
\text { vinos pasó al } \\
\text { suplemento } \\
\text { El viajero) }\end{array}$ & El País & 773.001 \\
\hline Dominical & $\begin{array}{l}\text { GRUPO ZETA, diarios locales del } \\
\text { grupo Prisa y otros diarios provinciales } \\
\text { (Deia, Diario de Noticias, Alerta, etc.) }\end{array}$ & 346.575 \\
\hline $\begin{array}{l}\text { Magazine de } \\
\text { El Mundo }\end{array}$ & El Mundo del siglo XXI & 323.917 \\
\hline
\end{tabular}

Como puede verse en la tabla anexa, cinco son los principales dominicales que se distribuyen en España: El Semanal, Magazine, El País Semanal, Dominical y Magazine de El Mundo. De ellos, en las fechas elegidas para realizar esta investigación (enero-diciembre de 2003) El Semanal, Magazine y Dominical incluían crítica o reseñas de vinos. No así El País Semanal ni Magazine de El Mundo. En el caso de la revista del grupo Prisa, ya se ha señalado que incluyó la sección 
"Beber", dedicada a la crítica enológica hasta octubre de 1999, en que fue trasladada al suplemento temático El Viajero. En cuanto al Magazine de El Mundo, si bien es cierto que durante el periodo estudiado no incorporó ninguna sección fija dedicada al vino, hay que aclarar que esta publicación mantiene uno de los mejores portales digitales dedicado a esta bebida. A "el mundo del vino" (http://www.elmundovino.com) se puede acceder directamente desde la página principal de elmundo.com.

En nuestro trabajo hemos analizado el suplemento El Viajero, de El País (440.226 ejemplares de difusión media en 2003), que es el que incluye una crítica enológica más completa, firmada por Carlos Delgado, la cual consta de una exhaustiva ficha técnica en la que se incluyen datos tales como marca, añada, nombre de la bodega, dirección, teléfono, tipo de vino, graduación, cepas, denominación, plazo de consumo, temperatura de servicio, precio y puntuación (sobre un total de 10 puntos). El texto, que generalmente consta de dos párrafos, suele dedicar el primero a facilitar una serie de informaciones sobre la bodega analizada, mientras que en el segundo se incluye la crítica de cata, propiamente dicha, haciendo especial hincapié en el aroma y sabor del vino. La longitud total de la crítica suele ser de tres cuartos de columna (en formato tabloide).

Otra de las publicaciones elegidas ha sido El Semanal, fundado en noviembre de 1987 y editado por Taller de Editores (Tesa), empresa que tiene al Grupo Vocento como principal accionista. El Semanal es el dominical que alcanza una mayor difusión en España (1.214.692 ejemplares a lo largo de 2002, según datos de OJD), ya que además de por los diarios ligados al grupo Vocento ( $A B C, E I$ Correo Español, El Diario Vasco, La Rioja, El Diario Montañés, El Comercio, Las Provincias, La Verdad, Sur, Ideal, Hoy y El Norte de Castilla) es también distribuido por otros importantes periódicos regionales y provinciales como La Voz de Galicia, Diario de León, Diario de Burgos, Diario de Navarra, Heraldo de Aragón, Diari de Tarragona, Menorca, Diario de Mallorca, Diario de Avisos, Diario de Ávila, Diario de Jerez y Diario de Cádiz.

El Semanal ofrece una sección denominada "Ella y él" dedicada a temas de servicios y consumo, en el que se incluye un apartado denominado "La cocina fácil de Martín Berasategui”, donde el afamado cocinero explica alguna receta. Junto a dicha receta se suele insertar un pequeño recuadro, bajo el cintillo de "El vino", en el que el crítico Juan Luis Recio analiza muy brevemente algún caldo. Se trata de una reseña erudita. La inexistencia de una ficha técnica y su brevedad (unas 100 palabras o 650 caracteres), parquedad en el lenguaje y tono general valorativo, acercarían este texto a lo que se conoce como reseña valorativa o erudita.

Otro de los dominicales analizados en el estudio es Magazine, editado (al 50\%) por los grupos Godó y Prensa Ibérica. Además de los diarios de dichas empresas - La Vanguardia, en el primer caso, y Diario de Ibiza, Diario de Mallorca, Faro de Vigo, Diario de Sevilla, La Opinión de Zamora, Información, La Nueva España, La Opinión de A Coruña, La Opinión de Murcia, La Opinión de Málaga, La Opinión de Tenerife, La Provincia y Levante, en el segundo-, durante 2003 esta publicación fue 
también distribuida por La Razón, El Día de Córdoba, y El Adelantado; alcanzando una difusión global de 785.810 ejemplares.

Magazine cuenta, dentro del bloque final dedicado a los servicios, con una sección fija destinada a la gastronomía, en la que se incluye una subsección, denominada "Vino", firmada por el crítico Alfred Rexach. Podríamos considerar que estos textos se encontrarían a medio camino de los ya descritos en los suplementos anteriores (El Viajero y El Semanal): ni son tan exhaustivos como en el caso de El País, ni tan lacónicos como los de la publicación del grupo Vocento. Suelen ocupar toda la altura de una columna (en formato revista) y aunque no constan propiamente de una ficha técnica diferenciada tipográficamente, sí que se destacan algunos datos importantes del vino analizado, como su denominación de origen, el tipo, la graduación y una calificación sobre un total de 20 puntos. Sin embargo, el titular es méramente descriptivo, recogiendo únicamente la marca analizada. El texto mantiene una estructura similar a la ya comentada en el caso de Carlos Delgado (crítico de El País): una primera parte en el que se realiza una introducción aclaratoria sobre la bodega o la zona analizada, y una segunda en la que se lleva a cabo la crítica de cata propiamente dicha, manteniendo un orden que puede considerarse estandarizado en este tipo de descripciones: color, aroma y sabor.

La última de las publicaciones analizadas es la dominada Dominical, suplemento arrevistado de fin de semana, nacido con dicho nombre en 2002, gracias a una iniciativa conjunta de los grupos Prisa y Zeta. Esta publicación alcanza una difusión de 346.575 ejemplares y en 2003 era distribuida por los diarios de Zeta (EI Periódico de Catalunya, Mediterráneo, Ciudad de Alcoy, El Periódico de Aragón, La Voz de Asturias, El Periódico de Extremadura, Córdoba, El Adelanto), los rotativos locales asociados a Prisa (Odiel Información, El Correo de Andalucía, Jaén, La Voz de Almería, El Día de Valladolid) y otros periódicos ajenos a dichos grupos, pero que han alcanzado un acuerdo para el reparto de Dominical (Alerta, Área, Deia, Diario de Noticias, Diario de Pontevedra, Diario de Soria, Diario de Teruel, Diario Palentino, El Periódico de Álava, El Progreso, La Prensa de Zamora, La Tribuna de Albacete y Lanza).

Dominical tiene una sección fija denominada "Gastronomía" en la que semanalmente se incluye un texto de Quim Vila sobre algún vino determinado. Nos encontramos con unas piezas mucho más cercanas a la reseña valorativa o erudita -es muy breve (unas 45 palabras, 220 caracteres), ausencia de ficha técnica, no hay una valoración en puntos del producto- que a la crítica, ya que estos textos también están dotados de algunas de las características propias de los géneros de opinión. Así el titular no siempre es informativo, pudiendo ser apelativo o incluso expresivo. Por otro lado, a pesar de no existir una ficha técnica, sí que se incluyen en el texto una serie de datos fundamentales tales como el nombre de la bodega, su teléfono, o el precio de la botella reseñada. Asimismo, si bien de forma muy escueta, el autor siempre desliza algunas observaciones personales acerca del vino catado ("...es una sinfonía de aromas a grosellas, cerezas y fresas, (...) perfume mágico y con una burbuja que se funde acariciando la boca"). 


\section{EL SUPLEMENTO EL VIAJERO (EL PAIS)}

\subsection{Introducción}

El País incluye su crítica de vinos dentro del suplemento El Viajero, que se distribuye los sábados, embuchado -junto al suplemento cultural Babelia- dentro del periódico. En el periodo estudiado, año 2003, este periódico publicó 38 críticas vinícolas, dentro de su apartado "Beber". Todas ellas fueron firmadas por Carlos Delgado, crítico enológico de este diario desde hace una quincena de años y director de publicaciones especializadas como Mi vino y Vinum. Además es autor, entre otras obras de gastronomía, de libros como Mis 200 vinos preferidos (Alianza, Madrid, 2003), El nuevo libro del vino (Alianza, Madrid, 2001), El libro del vino (Alianza, Madrid, 1997) o Diccionario de gastronomía (Alianza, Madrid, 1996).

A lo largo de 2003 hubo algunos sábados en los que El Viajero no contó con crítica vinícola, o ésta no se centró en un vino concreto. Así, los sábados 1 de febrero, 29 de marzo, 19 de abril (Sábado Santo, no hay prensa), 26 de abril, 17 de mayo, 31 de mayo, 23 de agosto, 25 de octubre, 29 de noviembre y 13 de diciembre no se publicó la sección "Beber" destinada al comentario enológico. Por otra parte, hubo una serie de sábados en los que esta sección no se dedicó a la crítica de una determinada marca de vino. Así, el sábado 4 de enero "Beber" acogió un comentario sobre diferentes guías de cata publicadas en España. Los sábados 18 de enero, 24 de mayo, 26 de julio y 4 de octubre se publicó la crítica pero no se dirigió a una determinada marca, sino que analizó un conjunto de caldos. El 18 de enero se comentaron seis vinos de maceración carbónica de distintas denominaciones. El 4 de mayo el texto aludió a seis bodegas de la Ribera del Júcar. El 26 de julio el objeto de la sección fueron seis cavas rosados. El 4 de octubre el turno le correspondió a seis botellas de albariño. Por último, cabe reseñar que el 6 de septiembre el objeto de estudio no fue el vino sino la sidra asturiana (seis marcas).

Es decir, se puede considerar que a lo largo de 2003, El Viajero publicó 39 críticas vinícolas, si bien una de ellas fue dedicada a comentar vinos de distintas zonas. El número de críticas dirigidas a un único caldo fue de 35.

Puede decirse que las críticas de El País responden a las características generales de dicha especialidad periodística. Constan de un título apelativo (44,7\% de los casos) o expresivo $(28,9 \%$ ) y de una completa ficha técnica en el que ofrecen los datos fundamentales del vino analizado: bodega, dirección de la misma, teléfono, Denominación de Origen, tipo de vino, cepas utilizadas, preferencia de consumo (corto, medio, largo plazo), temperatura de servicio, precio; así como la valoración que dicho caldo le merece al crítico, sobre un total de diez puntos. 


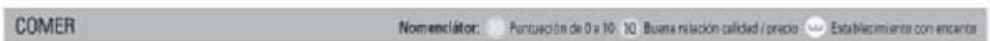

\section{Lomos y solomillos a la brasa de carbón de encina}

E. Fogón de Ftupe, un nuevo asador en San Pedro de Alcántara (Málaga)

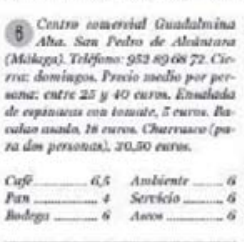

JOSE CAMLOS CAPEL I clipe Coimes, gue duran-
we afios foe propictario
de una acrediladacarni-
ceria en Marbella, es uno de los pocos especialistas
que en el proceloso gremio de la hosteleria expañola domina to dos los secretos de los asados a la parrilla I gual que cn ses dos locales antenores, en este nuevo r. eima inaporado, que recuerda mucstra sus dotes parz derar restra sis dotos para donar brasas de carbóo de encina.

Aunque su carta in acapuran sicte especialidades, to mejor es preguntat por el corte on el mejor punto de cámara. Quizà lomo y solomillo unidas por un hueso en formu de T), acaso del
chateaubriand (filete doble de la cabera del solomillo), del propio solomillo, si no del entroei y cl churrasco. Ninguna alusión a la falsa carne de bucy tan frecucnte en lor malos wadorca. Contes que proceden de vacimo toayor de raza retinta jaditarin. rada, que Gómez deja madurar ci fín entre dos $y$ tres sema. aas.

Fuerites templadas

Tras el tiempo de asado preecp. tivo, llegan a his mesas gruesios tacos de carne roja ya fileticados. eshalando arvenas a carbón con el punto de cocetón solicit: da. Porciones que se docan kercamente $y$ se presentan sobre los borribles plates refractatios los borribies platos reiractarios - afortunadamente co regre-

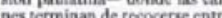
columeas de humo $y$ grasa Como corresponde a todo buen ase dor, cus pirzas presentan tres

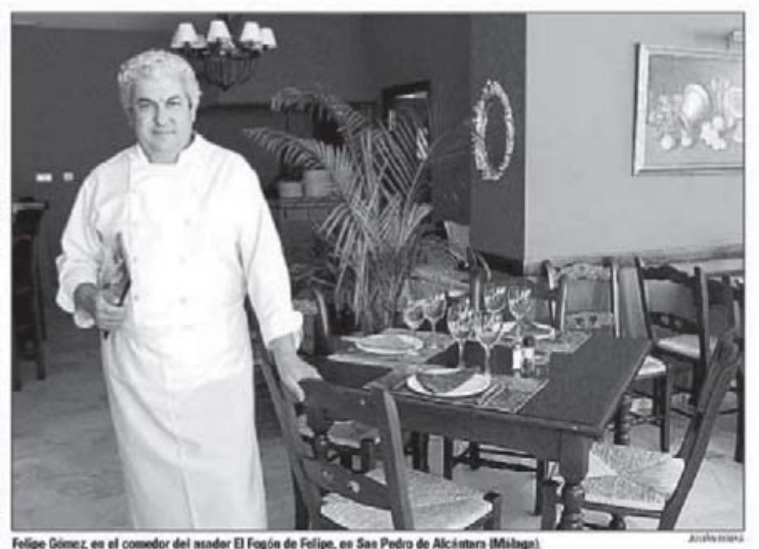

OTROS CINCO ESTRENOS EN LA COSTA DEL SOL

E J JOVENCismo Jese Carbs

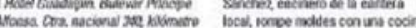

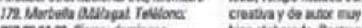

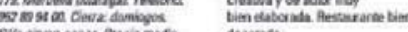

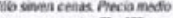

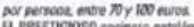

A rites nicioso cocinero catalis

testuratite Cocha moderna.

medren inearcieatita. Serticio

y bosega of nexh ina.

MC

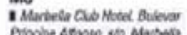

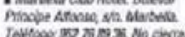

Pecib madla ciore $x$ y 85 movo

ES a Rincois más desentadado del

taneso Matbela $\mathrm{C}$. En sucarta,

Hatos de funion con rresertasione:

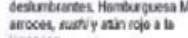

japonesis.

MED

1 Las Mencides, 12. Torrenefolos

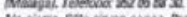

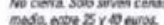

decerabo.

La Reband

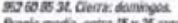

Meciv nutula, enve is

antierasion y par 1 c calcus de sos

tapas De sie on en aignas de las

mestan meras andor repertonte

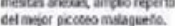

Lounge Suite

- Hoted Auente flamine Cru de Cidy, in in. Marteta. Tellitona

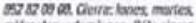
mivecoles y domiloss. Scito $\sin 10$ chase frecio matis, no

Sordocisu

Es uMA neecolfeA $y$ tanition in restausinte frabe Se cone sotre

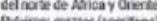
y tabes. Oe jiena nacke. tostada y crujicnte, con arnmas go), que prepara con lechales món iberico de calidad y un chopoov lios pisities (manzanat as. bodega muyelisiea eontieneal.

\section{Mesana}

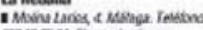

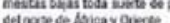

textnras: la costra superficial, rea humos la capa inmediata, lize ramente hecha, y el coravion, ro jo $y$ jugnoso.

Otras especialidades son cl cordero al horno (sólo por cricarcastellanos de raza chirra, y cl pollo a la brasa (macerndo al î. mon, detrasiado reguetnado. conos pruesos raeos de bacala Giral gruesos cacis de bacala aceite de oliva virgen. De guarmi. cía tomates de hureta al bor no y unas excepeionales patatis

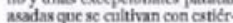
col en el término de Cancelad cMálesal.

Para emperar, cuatro ensala. das poco llamativas entre las que sobresale la de espinacas, unis buenas molicjas a la parmila, ja. rixo a la parrilla mediocre. Tam.

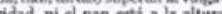
nid id, ai ct pan ceta a in altur punas marcas de relieve. Con buen tiempo merece la pena re la salarnandra $y$ se mocian de

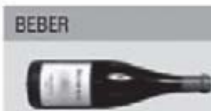

Cepas centenarias

Secastilla 200

Shourills. Cris, de Babbatn Ximal, Millinatora a,700.

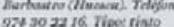

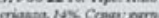
criasa, NK Craver gormind

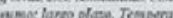

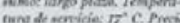

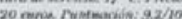

came os Dacasde

QURDA vodavia en Fspatia, venturueamente, un vipo, paradoficamente calva. do del arranque por cl aban-

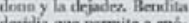
desidia que permite a enólogos aventurcros cumo Pcdro Aibar (Vinas dd Vero) recuperar cepas centena. tentegen el pacocosible tromo morreste de Somentrem
tano.

Aún me impresiona cl reciernbo del vipje en todotermeno por us camino deca. bras calodado que bordeaba las csoarpadas laderas. los derrapes frente al prod. pido, mientras subiamos pura cootemplar artubados hre cracains, Fi valle se lla. ma Secastilla $y$ en A nace ma Secastilla $y$ en d nace nefo de la zona, su historia de su autor. Una afirma de su autor. Una atrma. tencia de la entrañeble gar. nachia.

Tiene una nariz cilids. mediterrinea, dotada de una coloratura impactantes que se basa en la fruta madura, solani, $y$ sobre la que la cueciente crianza on roble franoes desarrolla un dialogos entre las espo clas y la madcra. Cuando se bebe hay un impacto ác. do yue prepara lis papitas para recioir sa carkada ta. medad, aun sin terminar lasy sirope el paladar arra. decida.

El texto en el que se se desarrolla dicha valoración suele tener una longitud aproximada de unas 200 palabras (entre 1.000 y 1.200 caracteres) y habitualmente se estructura en dos párrafos. En el primero de ellos se dan datos sobre la bodega analizada, como por ejemplo el nombre del propietario o el del enólogo. El segundo párrafo acoge la crítica propiamente dicha con la descripción cromática, aromática y de paladar referente del caldo valorado. 


\subsection{El objeto de estudio: DOs y tipos de vino}

Como puede verse en el cuadro anexo, las críticas vínicas de El País dedican una atención preferente a caldos de determinadas zonas, mientras que otras o no aparecen o tienen una presencia muy escasa. Tal y como se ha señalado con anterioridad, El Viajero destinó 38 sábados al análisis de vinos de distintas denominaciones de origen. No se ha tenido en cuenta en nuestra investigación sobre las Denominaciones de Origen (DO) la correspondiente al 18 de enero, en el que se analizaron seis vinos de maceración carbónica de la cosecha de 2002, correspondientes a diferentes zonas: Luberri (Rioja), Viñas del Vero (Somontano), Viña Urbezo (Cariñena), Erre Punto (Rioja), Prada a Tope (Bierzo) y Luis Alegre (Rioja). Las otras 3 reseñas colectivas señaladas se refirieron exclusivamente o a una única zona: Ribera del Júcar, y Rías Baixas, o a un mismo producto específico: el Cava. Por otro lado, hay que aclarar que el 26 de junio la crítica estuvo dedicada a un vino autraliano, el Dalwhinnie pinot noir 2001, por lo que este origen ha quedado también al margen de la gráfica realizada respecto a las denominaciones de origen.

A la vista de los datos analizados, puede afirmarse que El País primó claramente los vinos de una comarca concreta, "La Ribera del Duero", a la que pertenecen el $22 \%$ de las marcas seleccionadas. En segundo lugar se encontraría el bloque denominado "Vinos de la tierra", con cuatro críticas. Según la "Ley de la viña y el vino de 2003", los vinos de la tierra son vinos de mesa (esto es, sin estar amparados por una Denominación de Origen) que cumplen dos requisitos:

a) Que el territorio vitícola del que proceda, independientemente de su amplitud, haya sido delimitado teniendo en cuenta unas determinadas condiciones ambientales y de cultivo que puedan conferir a los vinos características específicas.

b) Que expresen la indicación geográfica, el área geográfica, las variedades de vid y los tipos de vinos amparados, el grado alcohólico volumétrico natural mínimo y una apreciación o una indicación de las características organolépticas.

Somontano y Navarra, con 3 reseñas; y Vinos de Madrid, Penedés y Cariñena, con 2, serían las siguientes denominaciones analizadas, en cuanto a número de críticas se refiere. En total, a lo largo de 2003 la sección de crítica enológica de El País prestó especial atención a 18 DOs españolas. Al margen de las mismas, como se ha comentado, se incluyeron 4 vinos de la Tierra, y un vino sin DO: Quincha Corral 2000, de Bodega Mustiguillo de Valencia, cuya crítica fue publicada el 25 de enero de 2003. Al respecto, no obstante, hay que matizar que en octubre de 2003 Bodega Mustiguillo obtenía de la Consellería de Agricultura de la Generalitat de Valencia la denominación de "Vino de la tierra El Terrerazo"; lo que podría ser considerado como un primer paso hacia la creación de una futura DO de vino de pago (como los ya existentes Dominio de Valpusa y Finca Elez).

En total, dejando al margen los apartados de "Otros", "Vinos de la Tierra" y "Vinos sin denominación de origen", un total de 17 DOs fueron mencionadas en las críticas de El Viajero. 
En lo que a la puntuación se refiere, el ranking en lo que respecta a catas individualizadas quedaría en sus diez primeros puestos de la siguiente forma (en caso de empate a puntos se ha consignado en primer lugar el vino de menor precio):

1- Artadi Viña El Pisón. Tinto Crianza 2000. Bodega: Artadi-Cosecheros Alaveses (DOC Rioja). 9,7 puntos (95 euros).

2- Matallana 2000. Tinto Crianza. Bodega: Ca de Vinos Telmo Rodríguez (DO Ribera del Duero). 9,4 puntos (50 euros).

3- Tinto Valbuena. Crianza 1998. Bodega: Vega Sicilia. (DO Ribera del Duero). 9,4 puntos (50 euros).

4- Care 2001. Tinto Crianza. Bodega: J.B. Añadas. (DO Cariñena). 9,3 puntos (12 euros).

5- Enate Merlot-Merlot. Tinto Crianza 2000. Bodega: Enate (DO Somontano). 9,3 puntos (20 euros).

6- Nebro. Tinto Reserva 1998. Bodega: Hermanos Cuadrado García (DO Ribera del Duero). 9,3 puntos (72 euros).

7- Finca L'Argatá 2000. Tinto crianza. Bodega: Joan d'Anguera (DO Montsant). 9,2 puntos (12 euros).

8- Malboré 2000. Tinto Crianza. Bodega: Pirineos (DO Somontano). 9,2 puntos (18 euros).

9- Secastilla 2001. Tinto crianza. Bodega: Secastilla (DO Somontano). 9,2 puntos (20 euros).

10- Pago de Carraovejas. Vendimia Seleccionada 99. Tinto Crianza. Bodega: Pago de Carraovejas (DO: Ribera de Duero). 9,2 puntos (56 euros).

Entre estos diez vinos que alcanzan una mayor puntuación nuevamente son los Ribera del Duero los que alcanzan una mayor presencia (4 marcas), seguidos con 3 por Somontano, mientras que Rioja, Montsant y Cariñena cuentan con un único representante.

Si nos fijamos en las Comunidades Autónomas a las que pertenecen los vinos analizados, se observa una presencia preponderante de los vinos de Castilla-León (10 críticas, un $27 \%$ del total), seguidos de los de Aragón (6 reseñas, un 16\%), de los de Castilla-La Mancha (5, un $14 \%$ ) y de los de Catalunya (4, un 11\%). A continuación se encontrarían los caldos de Navarra (3), Comunidad Valenciana y Madrid (2), y Andalucía, Galicia y País Vasco (1). Curiosamente, a lo largo del 2003 El País no dedicó ninguna reseña individualizada a ningún vino producido en la autonomía de La Rioja, ya que la única marca acogida a la DOC Rioja que se 
incluyó en la sección "Beber", Artadi Viña El Pisón, pertenece a una bodega ubicada en la localidad alavesa de Laguardia (País Vasco).

El precio medio de los vinos analizados durante 2003 en críticas individualizadas fue de 24,6 euros, mientras que su puntuación media (sobre un máximo de 10) fue de 8,8 puntos.

En cuanto al tipo de vino analizado, destaca la presencia de los tintos (84\% de las críticas), seguidos de los blancos $(11 \%)$ y del cava $(5 \%)$. No hubo ninguna crítica dedicada al vino rosado (sí, en cambio al cava rosado). Por último, si reparamos en la antigüedad de los vinos, nos encontramos con 29 crianzas, 5 vinos jóvenes y 3 reservas.

El País: DO analizadas en 2003

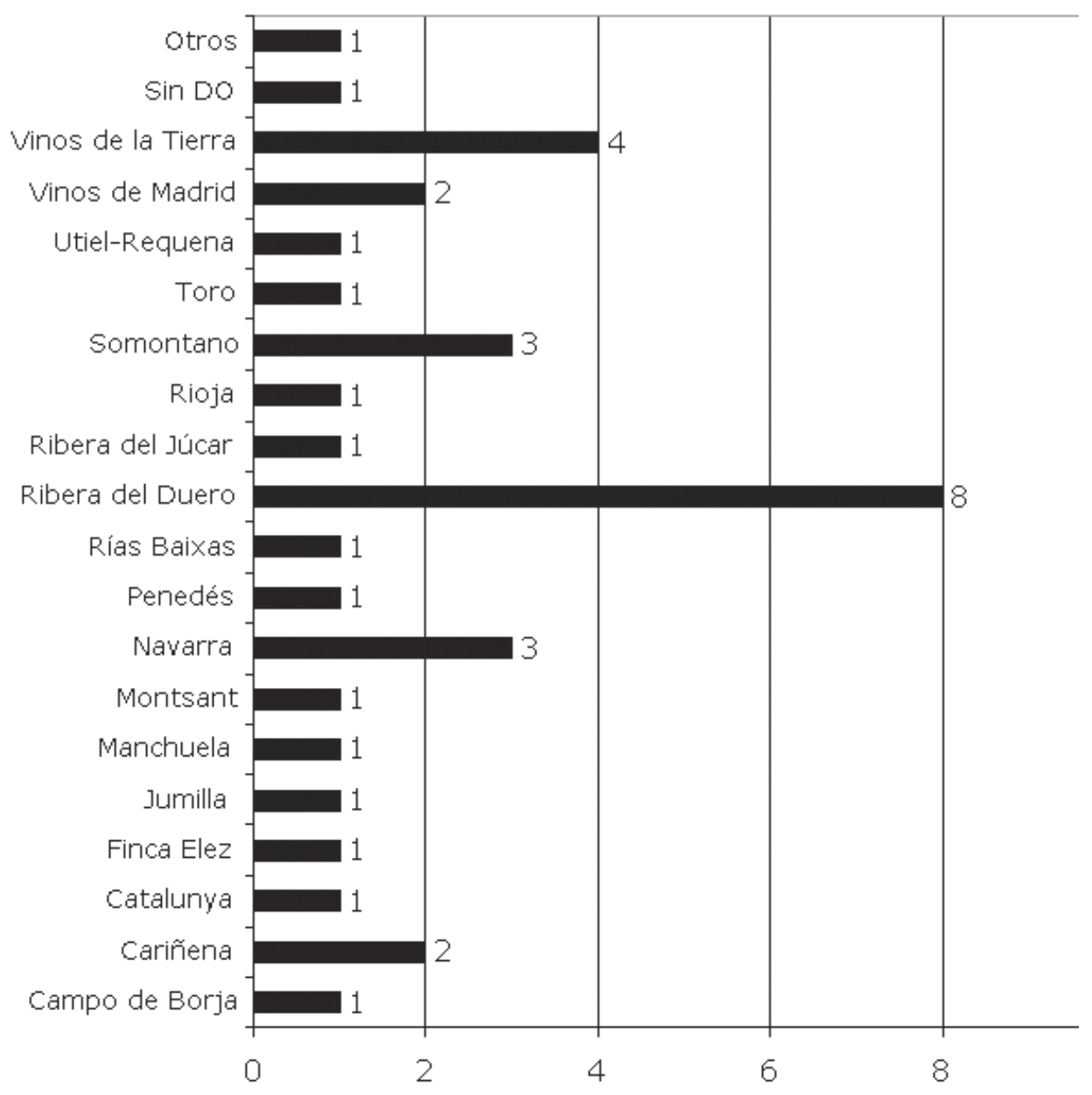




\section{El País: Presencia de las distintas DO en $2003(\%)$}

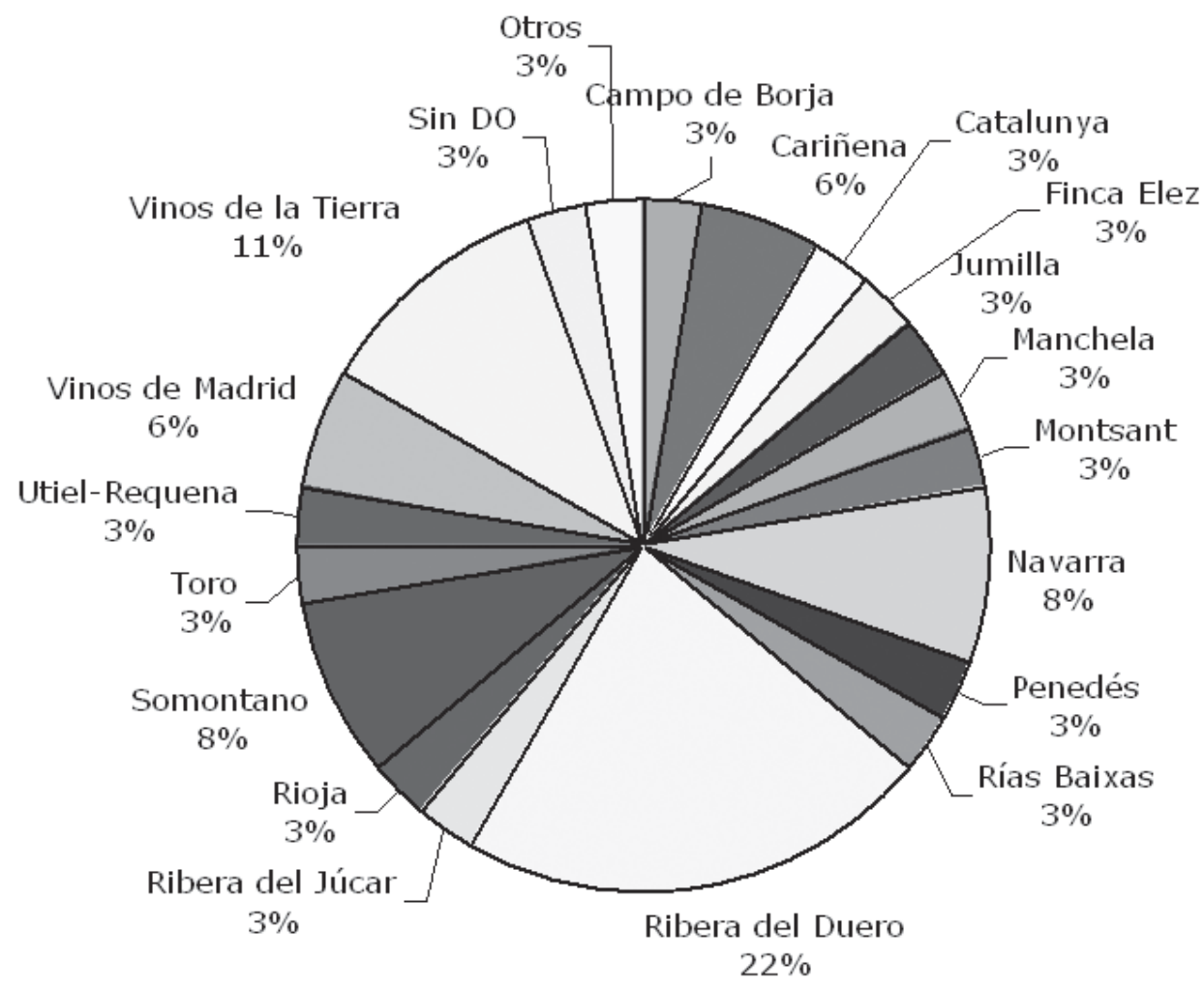




\section{No de vinos criticados por Autonomías}

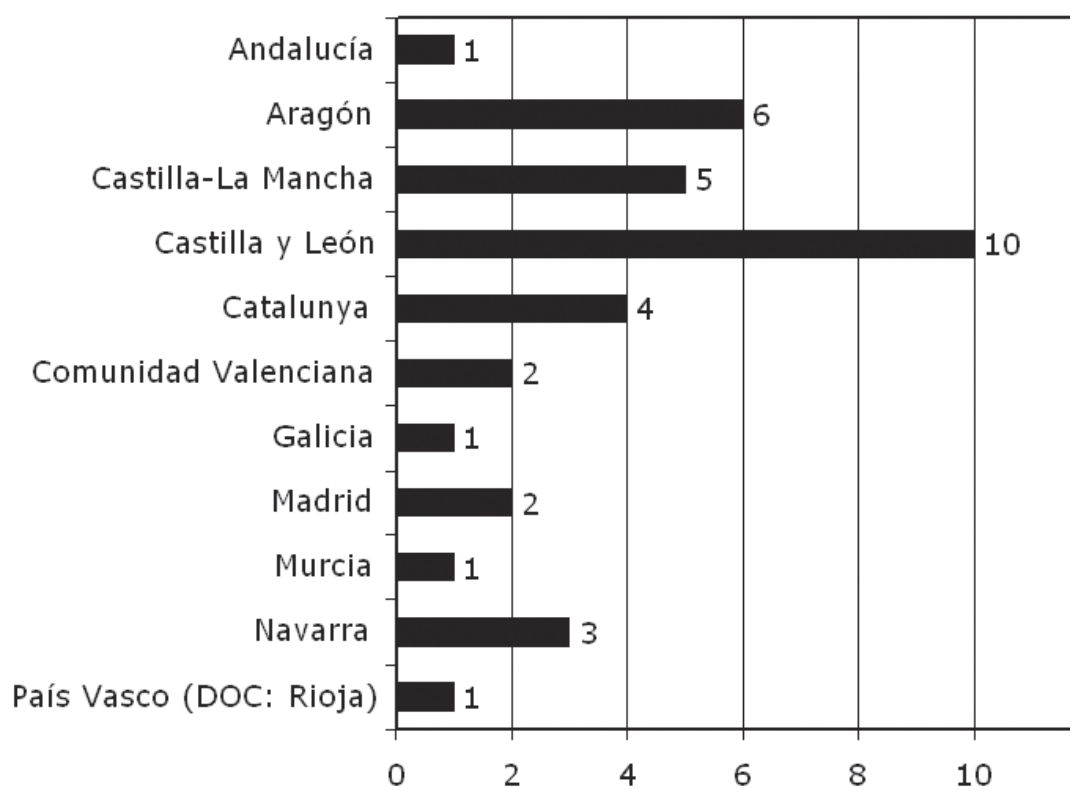

\section{No de vinos criticados por Autonomías (\%)}

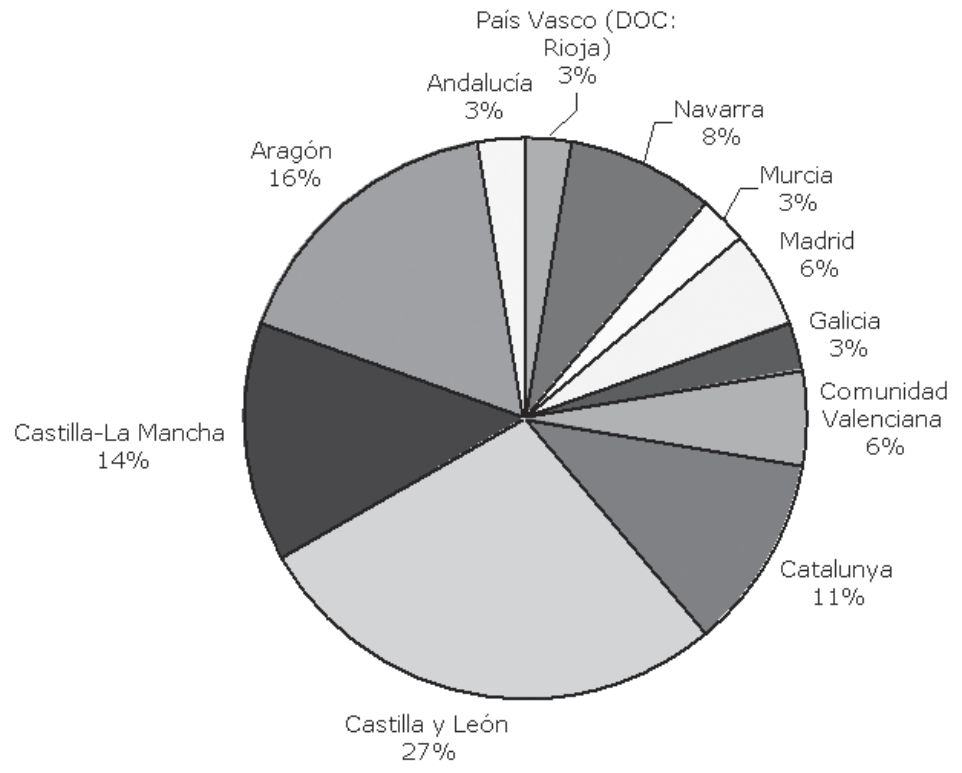


Tipo de vinos criticados

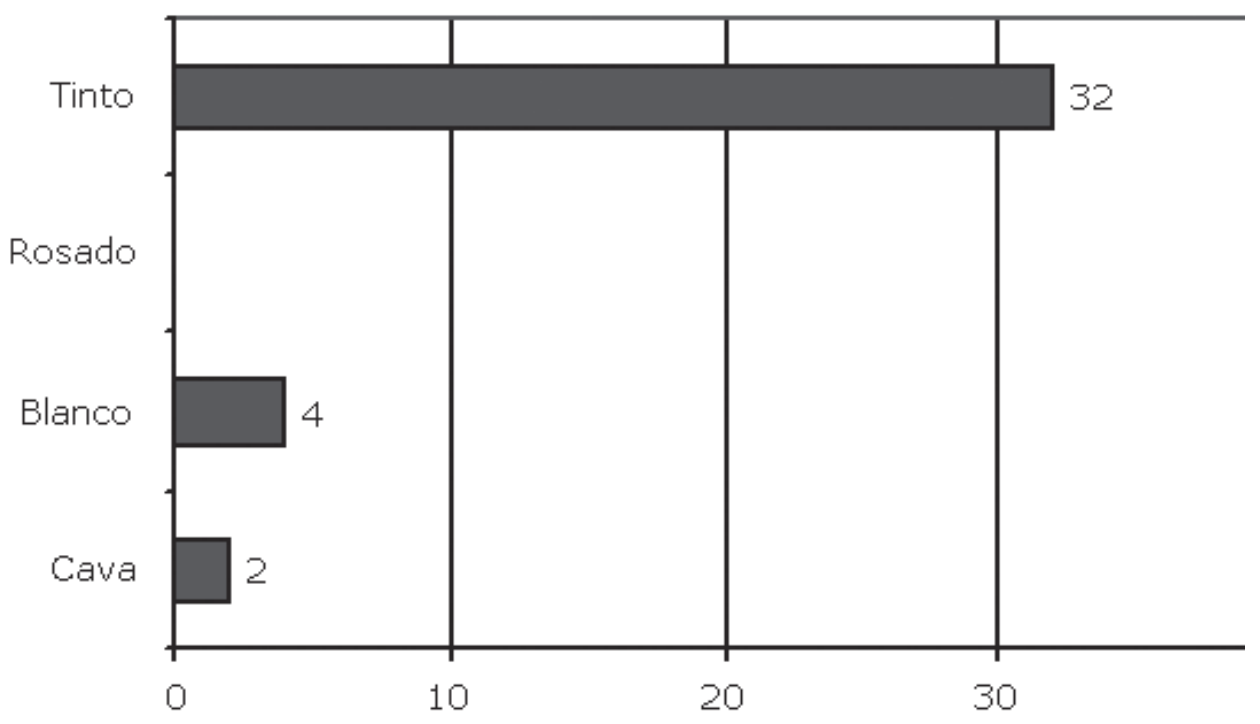

Tipo de vinos criticados (\%)

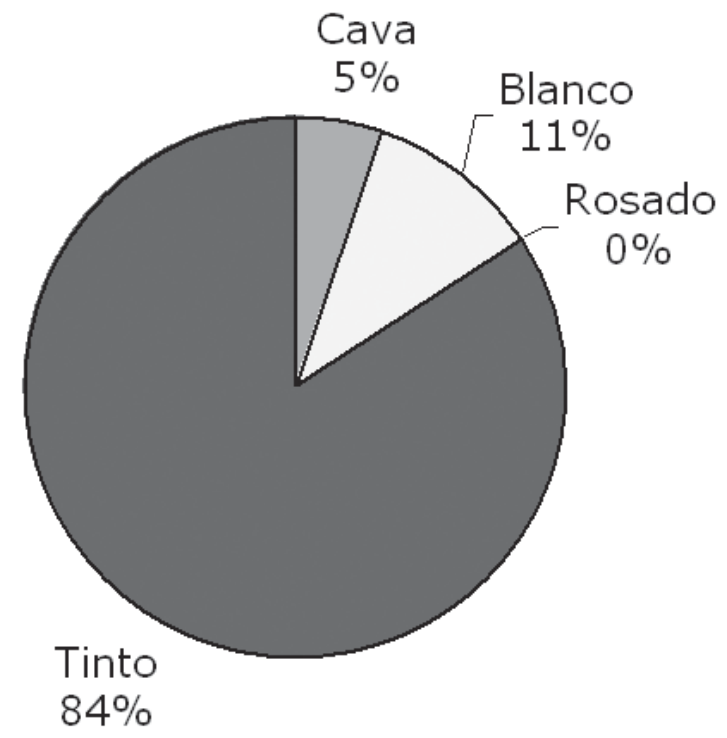




\section{Vejez de los vinos criticados}

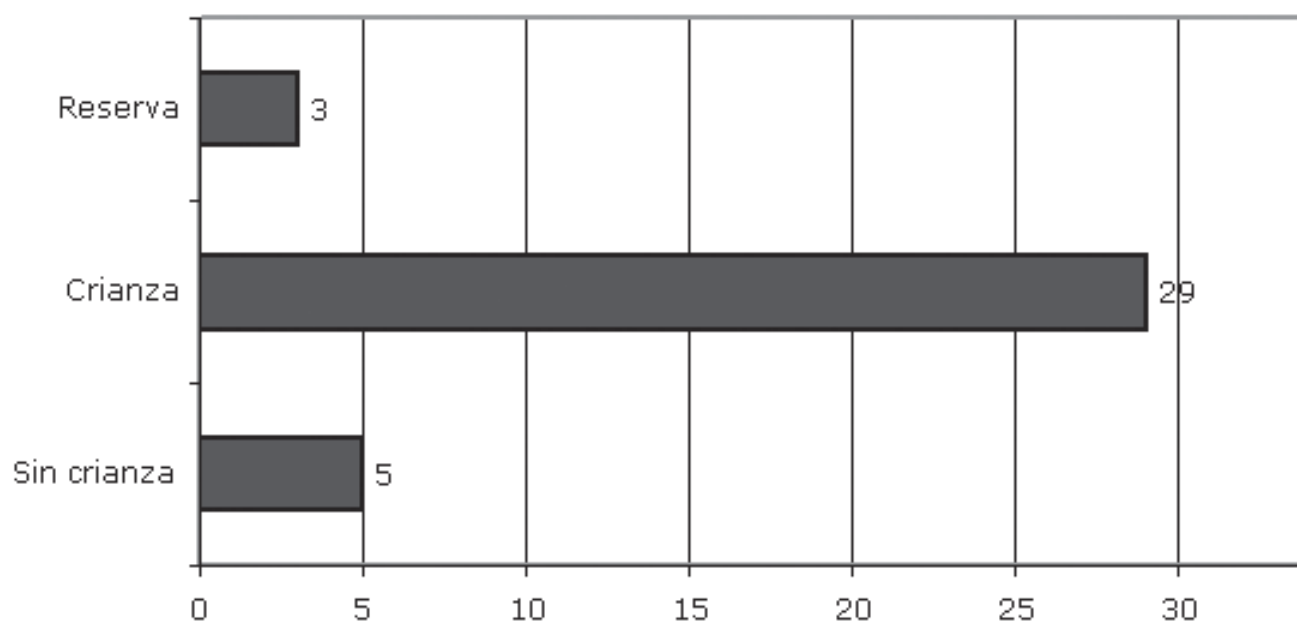

Edad de los vinos (\%)

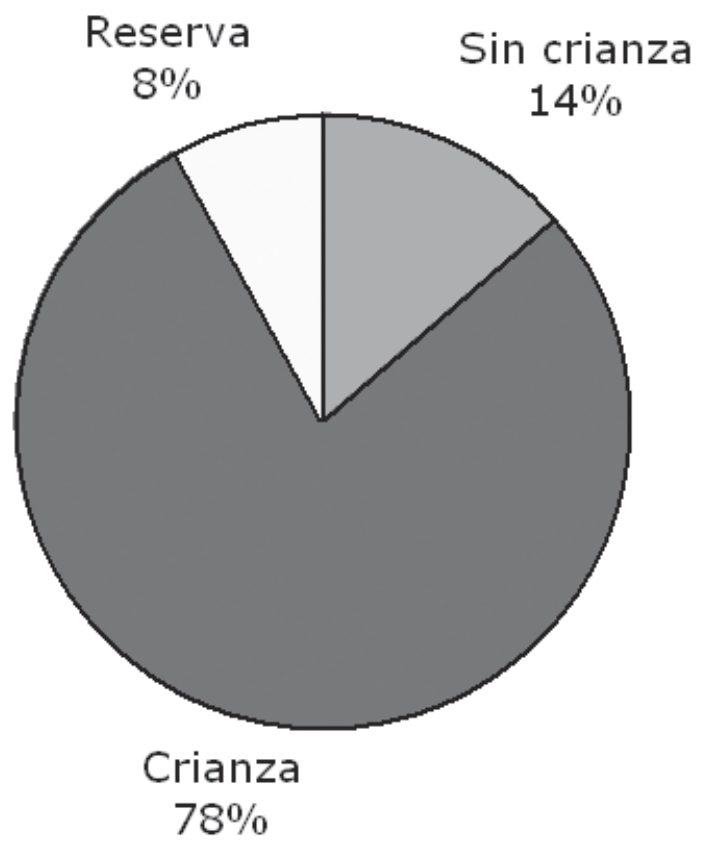




\section{EL SEMANAL DEL GRUPO VOCENTO}

\subsection{Introducción}

Como ya se ha señalado con anterioridad, el dominical El Semanal -nacido en 1987- es el que mayor difusión alcanza en el Estado entre este tipo de productos (1.214.692 ejemplares en 2002). Está editado por Taller de Editores S.A. (TESA), que en 2003 tenía como principales accionistas al Grupo Vocento (67\%), a la empresa propietaria de Heraldo de Aragón (9\%), a Federico Doménech -Las Provincias de Valencia- (14\%) y La Información (9\%). Esta publicación era distribuida en el momento de realizarse esta investigación (año 2005) por 25 diarios (todos los del grupo Vocento, más una serie de periódicos de ámbito regional, provincial y local, como La Voz de Galicia, Heraldo de Aragón o Diario de Navarra, entre otros). Atendiendo a la difusión global de este suplemento, podría afirmarse que su crítica enológica sería la, al menos potencialmente, más leída de cuantas se publican en la prensa española.

Los comentarios referidos a esta bebida suelen aparecer en una subsección denominada "El vino", que a su vez se integra en una sección más amplia: "La cocina fácil de Martín Berasategui". Todo este apartado gastronómico forma parte del bloque general de servicios y consumo del suplemento, que responde al cintillo de "Ella y él". El responsable de la sección "El vino" es el crítico Juan Luis Recio.

Tal y como ha quedado previamente explicado, estos textos suelen ser bastantes breves -unas 100 palabras- y carecen de ficha técnica, por lo que, en apariencia, podrían parecer más cercanos a la reseña que a la crítica propiamente dicha. Además, tampoco existe un titular periodístico, sino que el encabezado corresponde a la marca del vino que se analiza. Sin embargo, no se puede afirmar que nos hallemos ante un texto informativo, estamos claramente ante una reseña valorativa. Existe una descripción de cata, en la que el autor presenta sus propias valoraciones, referidas al color, aroma y sabor. A falta de una ficha técnica diferenciada, datos como el precio de la botella aparecen dentro del bloque de texto. Esporádicamente, aunque no siempre, se hace también mención a la Denominación de Origen y a la variedad de uva empleada. A diferencia de lo que ocurre en otras publicaciones, el dominical de Vocento no ofrece una valoración en puntos de los vinos descritos.

En 2004, la edición digital de El Semanal (www.clubelsemanal.com), recogía una sección patrocinada por el Grupo Faustino: (www.clubelsemanal.com/vinos), en la que cada semana aparece el mismo texto que Juan Luis Recio escribe para la versión en papel de la revista, sólo que, esta vez sí, acompañado de una completísima ficha técnica en la que se recogen datos tales como tipo de vino, bodega, zona, cosecha, envejecimiento, composición varietal, graduación alcohólica, volumen de la botella, precio y fecha de cata. Además, desde dicha página web los lectores puede adquirir distintos vinos.

A lo largo de 2003, El Semanal publicó un total de 49 críticas enológicas. La sección "El vino" se publicó también durante el mes de agosto. 

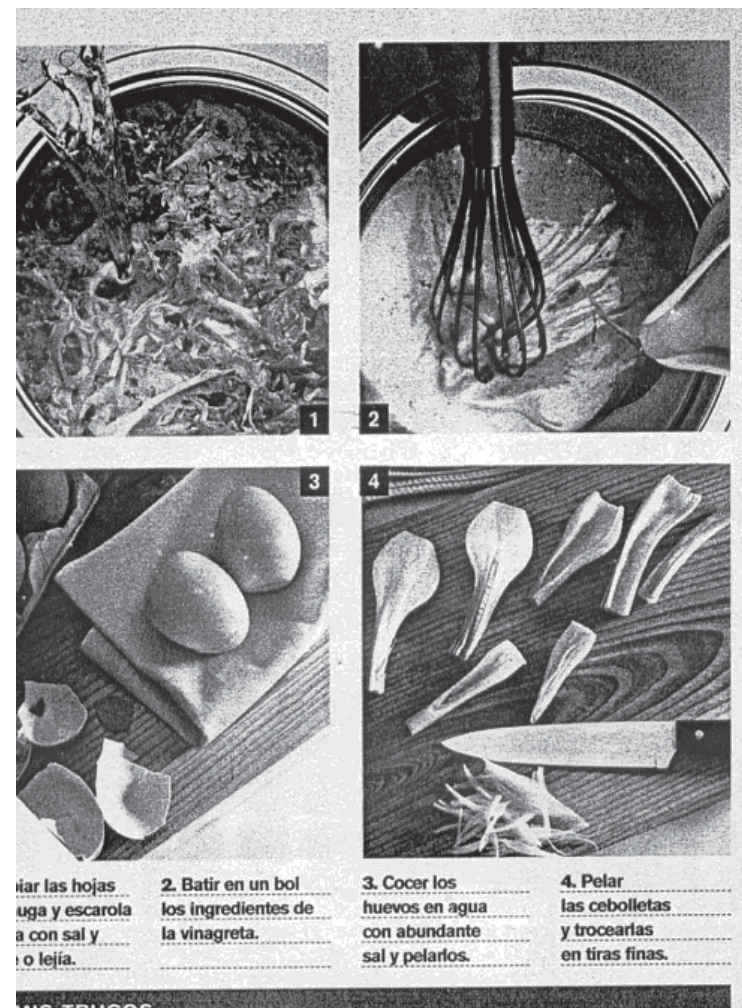

to lejia.

\begin{tabular}{ll}
\hline MIS TRUCOS & \\
\hline la misma & nuestro gusto. \\
e lechuga y & Se puede añadir \\
la, la & remolacha, \\
da se puede & pepinillos en \\
zar con toda & vinagre, dados de \\
le & queso fresco, \\
lentes a & maices, zanahoria
\end{tabular}

rallada, tiras de con unas gotas de
mojama, frutos salsa de soja, salsa secos tostados, Worcestershire, distintos tipos de zumo de limón, etc. germinados, etc. El Todo depende alin̄o también se de la imaginación puede enriquecer

\section{EL VINO}

JCA VALPIEDRA RESERVA 1998

las cepas del homónimo viñedo propio que la familia Martinez Bujanda ee en Fuenmayor, se elabora este vino tinto, acogido a la D.O.C. Rioja, ha envejecido durante 18 meses en barricas nuevas de roble francés por ciento) y americano ( 15 por ciento). Es un caldo de color rojo cepicota cubierto, que desenvuelve aromas limpios y agradables con redos a frutos negros y balsámicos. Un vino muy sabroso, equilibrado y que combina bien con muchos y variados platos. Siempre debe seren la mesa a una temperatura de unos 18 grados. Precio aproxima16,70 euros.

DOR JUAN WIS RECIO

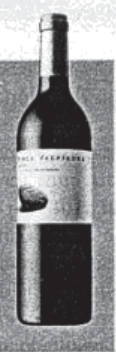

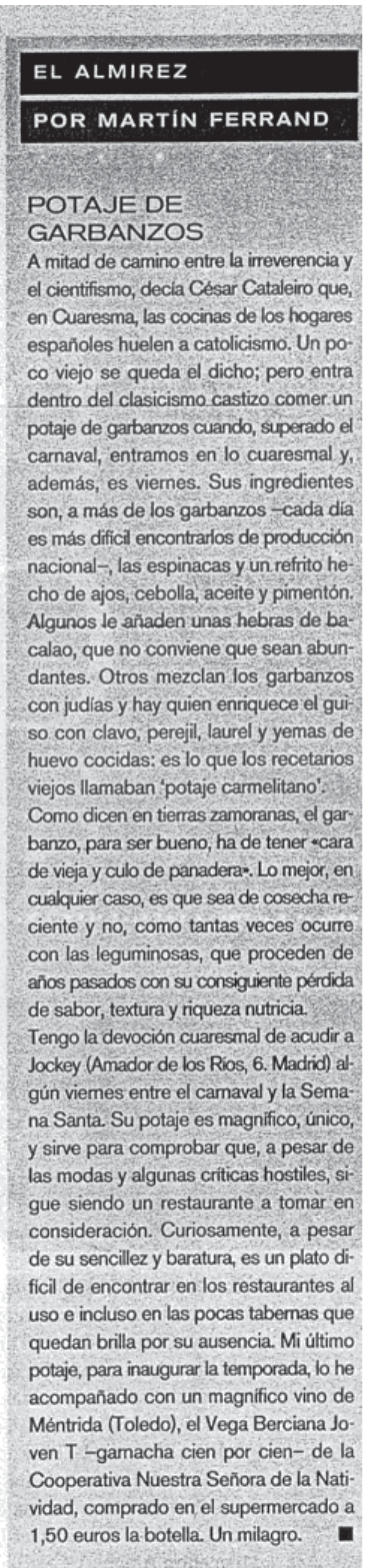

15 de febrero $\mathrm{E}$ 


\subsection{El objeto de estudio: DOs y tipos de vino}

La Rioja (un $28 \%$ de las críticas) y Navarra (14\%) son claramente las denominaciones que mayor número de análisis merecieron a lo largo de 2003. La atención merecida por los vinos del resto de las zonas queda muy alejada de estas dos. De hecho, en cuanto a número de críticas, los denominados "vinos de la tierra" -4 apariciones- quedarían por delante de DOs como Somontano o Ribera de Duero 3 menciones cada una-. Dos textos merecieron los caldos de Rueda, Rías Baixas, Penedés, La Mancha y Jumilla. Mientras que las denominaciones Yecla, Toro, Sierras de Málaga, Monterrei, Cava y Catalunya merecieron un único representante. En total, "Vinos de la Tierra" y "Otros" (vermouth, champagne) al margen, un total de 15 DOs fueron analizadas en la sección de Juan Luis Recio.

Por lo que respecta a las Comunidades Autónomas a las que pertenecen los vinos aludidos por El Semanal vemos que, al igual que sucedía con las denominaciones de origen, la zona con mayor representación es La Rioja (11 apariciones, un $24 \%$ del total), seguida de Navarra (7 menciones, un $16 \%$ ), Castilla y León (6, un $13 \%$ ), y de Catalunya (4, un $9 \%$ ). Con 3 reseñas cada una se situarían los caldos del País Vasco (todos ellos incluidos en la DOC Rioja), Murcia, Galicia, Castilla-La Mancha y Aragón. Por último, se publicaron dos textos referidos a vinos de Andalucía. Cabe destacar la preponderancia en las críticas de El Semanal de las bodegas del triángulo País Vasco-Navarra-La Rioja (un 46\% del total).

A diferencia de lo que ocurre con otros críticos analizados, Juan Luis Recio no puntúa los vinos incluidos en sus textos, aunque sí indica el precio aproximado de los mismos. El precio medio de los vinos reseñados durante 2003 fue de 14,79 euros.

Por lo que respecta al tipo de vino analizado, el tinto es el que atrae una atención preferente (34 menciones, un $70 \%$ del total), seguido del blanco (9 menciones, un $18 \%$ ), del rosado (3 apariciones, $6 \%$ de las críticas) y del cavachampagne (2 casos, un 4\%). En el apartado de "Otros" figuraría un texto relativo a un vermouth. Por último, si nos fijamos en la antigüedad de los vinos, nos encontramos con 20 vinos jóvenes, 11 crianzas, 9 reservas y 2 gran reservas. 
104 La selección temática de la crítica de vinos en la prensa española

Vocento: Do analizadas en 2003

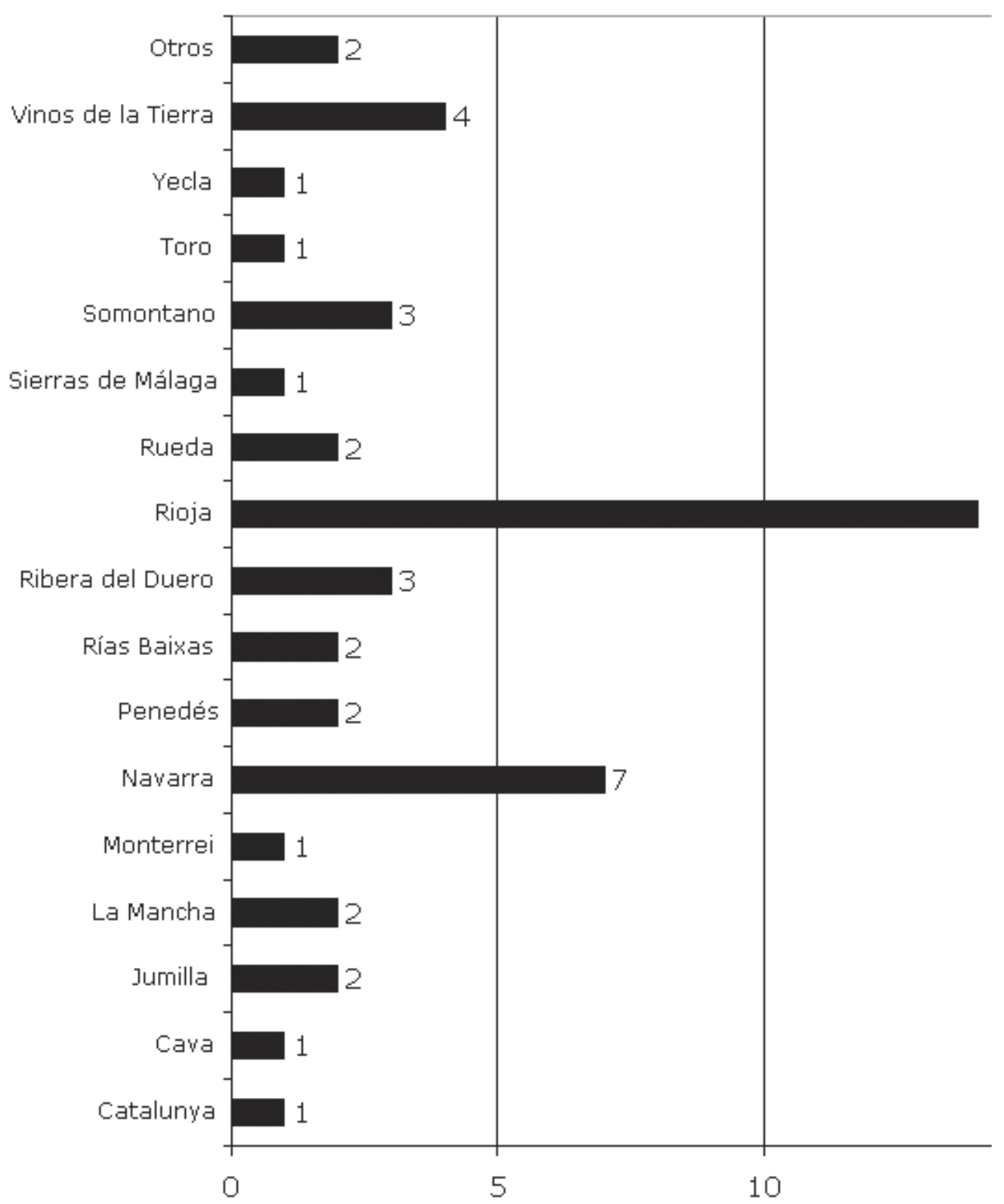


Vocento: Presencia de las distintas DO en $2003(\%)$

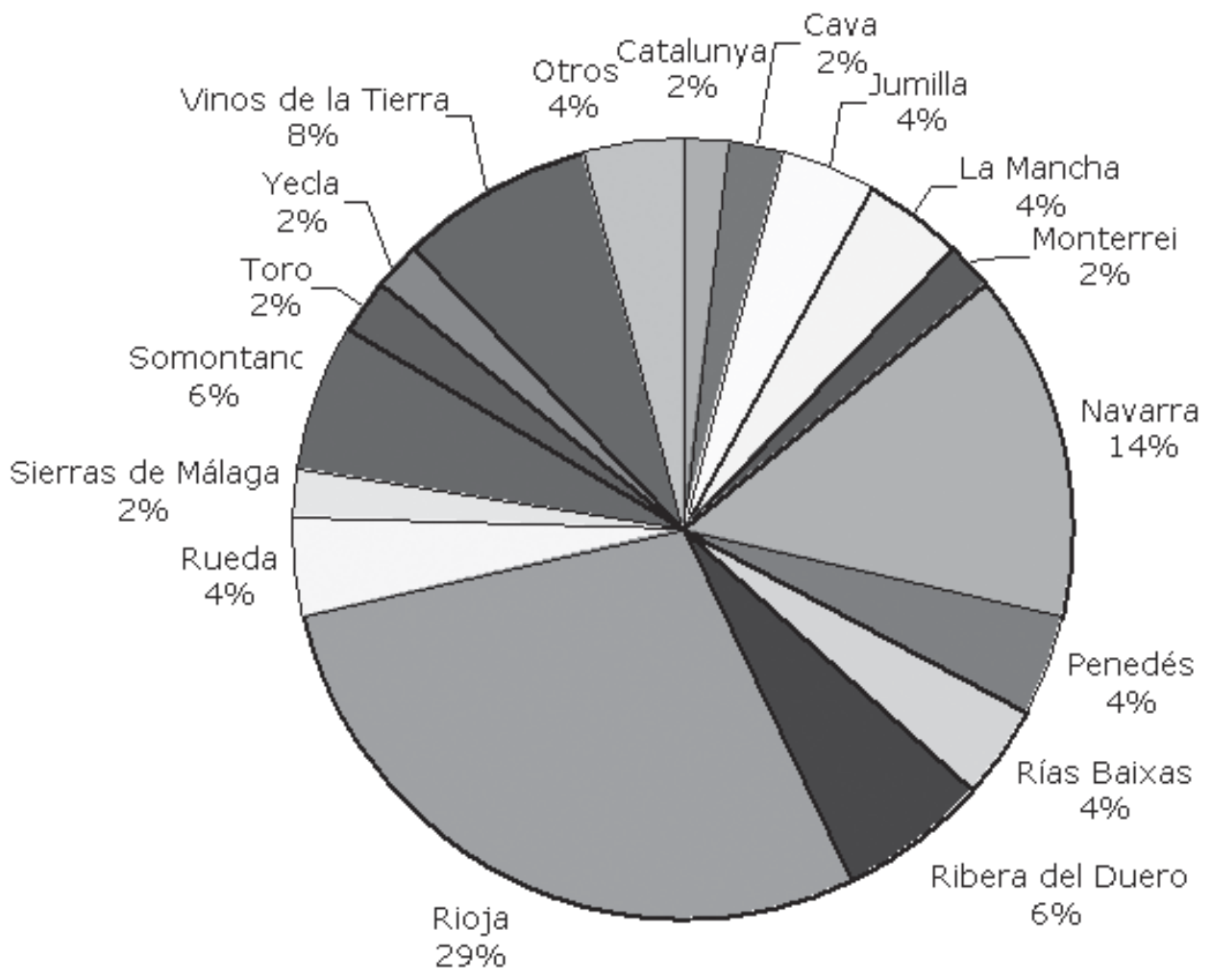




\section{$N^{0}$ de vinos criticados por Autonomías}

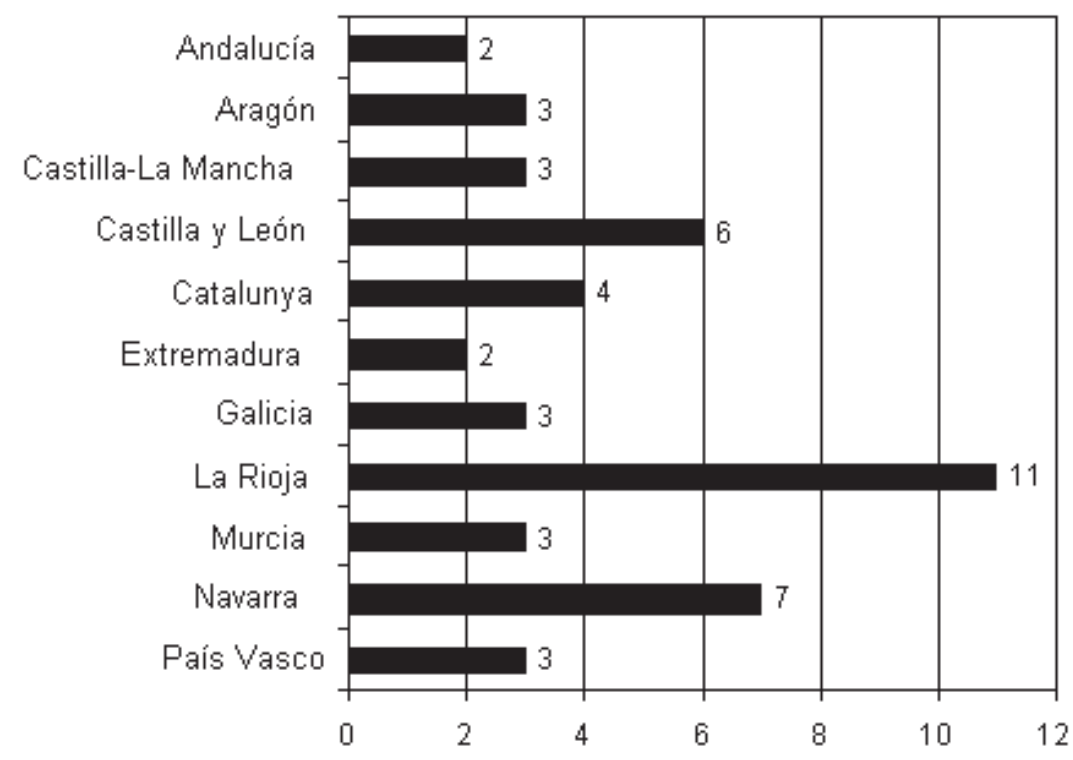

$N^{0}$ de vinos criticados por Autonomías (\%)

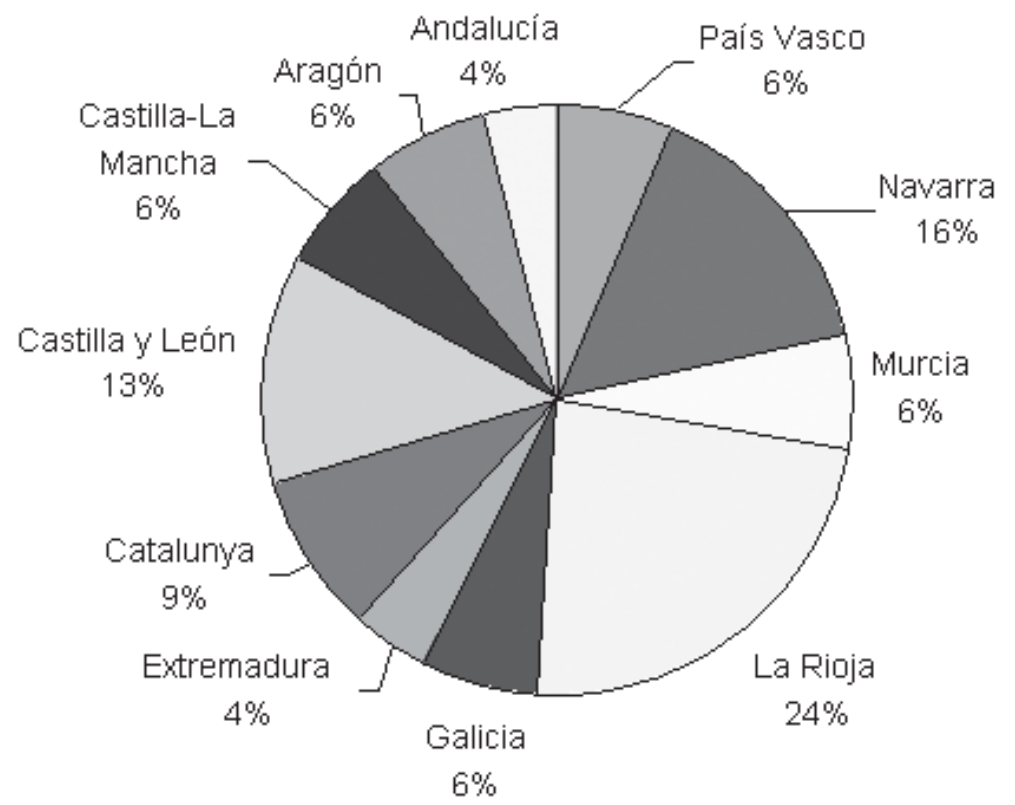




\section{Tipo de vinos criticados}

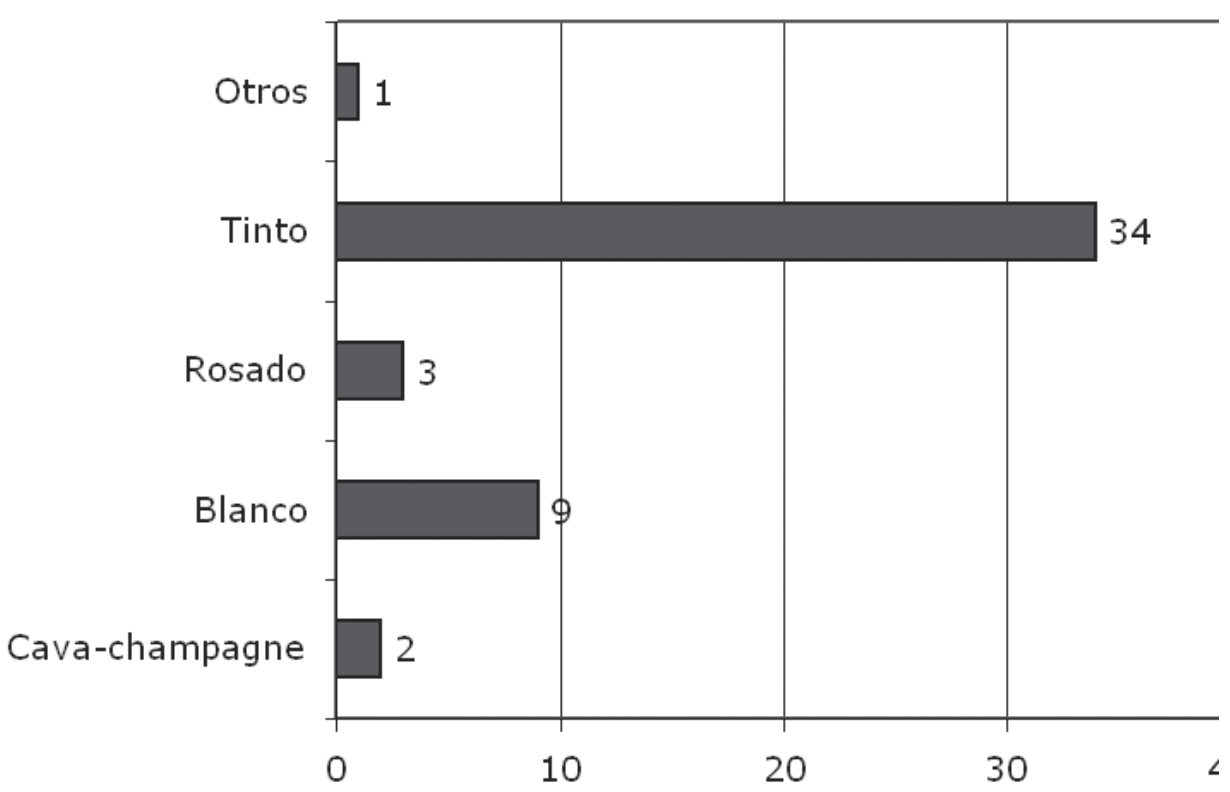

Tipo de vinos criticados (\%)

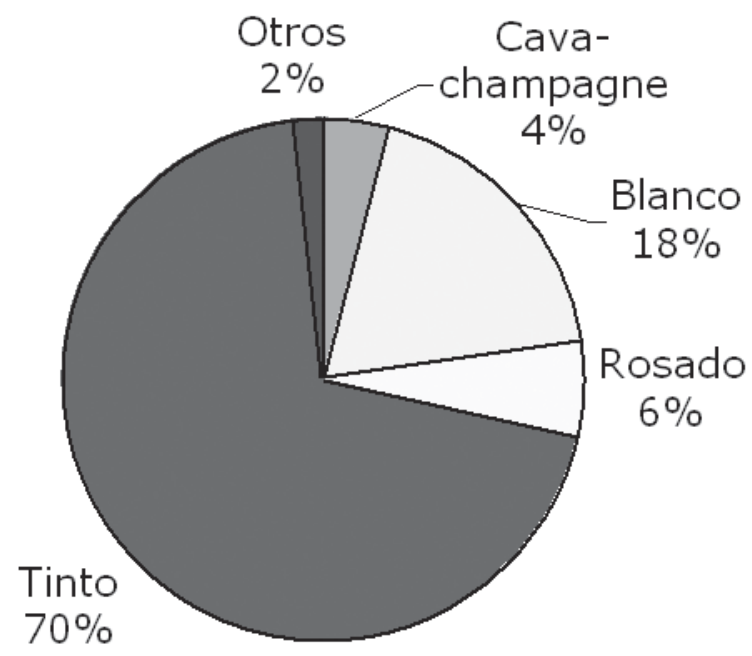




\section{Edad de los vinos criticados}

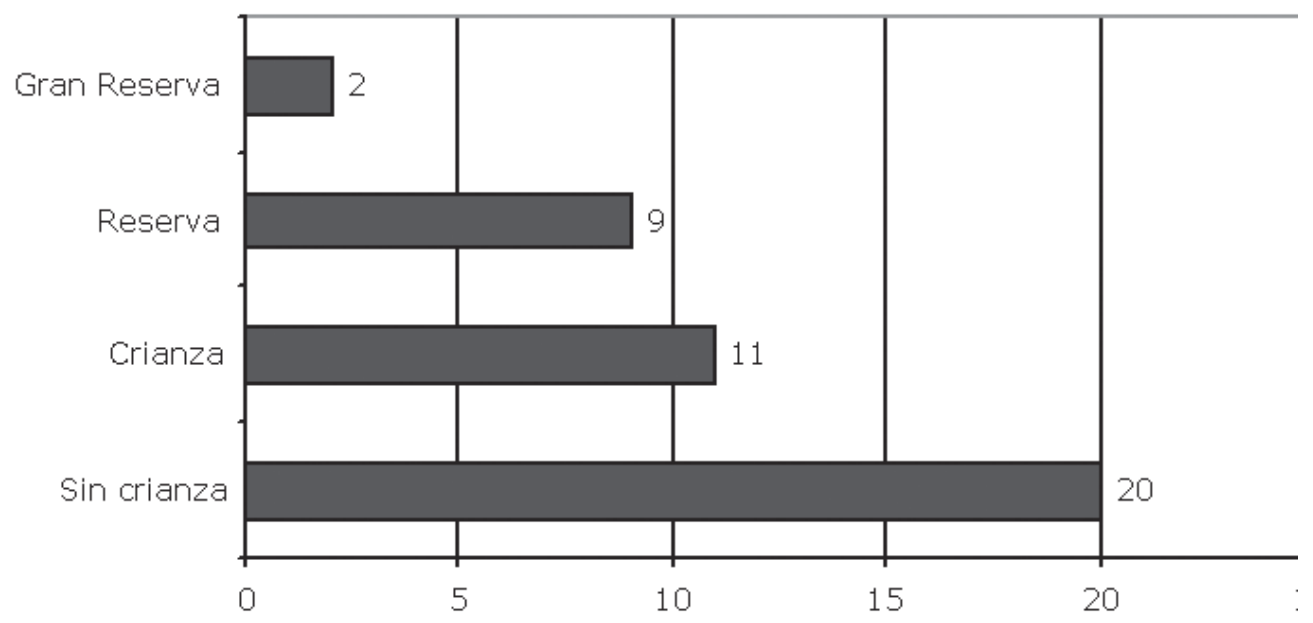

Edad de los vinos (\%)

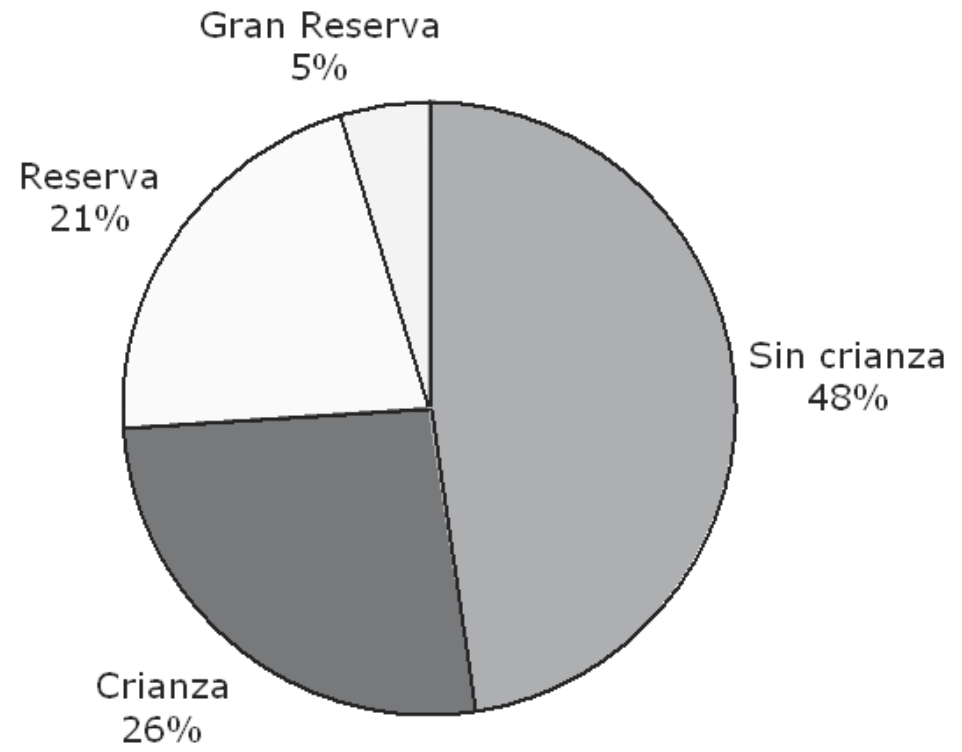




\section{MAGAZINE}

\subsection{Introducción}

Magazine es el nombre del suplemento, arrevistado y en papel couché, de fin de semana, editado al $50 \%$ por los grupos Godó y Prensa lbérica y que alcanzó a lo largo de 2003 una difusión global de 785.810 ejemplares, lo que le convirtió en el segundo producto de estas características más distribuido, tras El Semanal del Grupo Vocento.

Esta publicación es distribuida por La Vanguardia (Grupo Godó), así como por los matutinos del Grupo Prensa Ibérica -Diario de Ibiza, Diario de Mallorca, Faro de Vigo, Diario de Sevilla, La Opinión de Zamora, Información, La Nueva España, La Opinión de A Coruña, La Opinión de Murcia, La Opinión de Málaga, La Opinión de Tenerife, La Provincia y Levante. Asimismo, durante 2003 esta publicación fue también distribuida por La Razón, El Día de Córdoba, y El Adelantado.

Magazine incluye su crítica enológica -bajo un cintillo con el nombre de "Vino"dentro del bloque dedicado a la gastronomía. El responsable de este apartado es el crítico Alfred Rexach, autor de obras como Vins i cabes de Catalunya (Edicions Lisard, Barcelona, 2000) o Guía de vinos, 1997 (Columna edicions, Barcelona, 1997). Los textos podrían situarse a medio camino de lo ya comentado para El País y El Semanal del Grupo Vocento. No son tan exhaustivos como aquellos, ni tan lacónicos como estos últimos. Aunque no existe una ficha técnica tipográficamente diferenciada, Alfred Rexach sí que subraya en un estilo y tamaño de letra diferente al del resto del texto, la marca del vino, la Denominación de Origen, el tipo (tinto crianza, blanco, etc.), su graduación, y una calificación sobre un total de 20 puntos (las de El País son sobre 10 puntos). Sin embargo, se echa en falta el dato referido al precio de la botella, algo que sí aportan los dos críticos anteriormente citados. 
http://dx.doi.org/10.12795/Ambitos.2006.i15.06

\section{gastronomía}

\section{Mari Carmen}

Matalebreras (Soria). Familiar, limpio y hospitalario, este establecimiento sobrevive al género de restaurantes de carretera con identidad. Su oferta permite hacer un confortable alto en el camino para recrearse con lo que ofrecen un menú discreto, pero bueno, y una carta constituida por platos de verduras del tiempo, carnes y pescados poco costosos, elaborado todo ello con gracia.

En temporada ofrecen, por ejemplo, perdiz de caza y alcachofas guisadas, yen todo momento, unas muy buenas croquetas caseras, cabrito al ajillo y jamón ibérico. La gerencia y la atención son notables.

A pie de carretera y muy concurrido habitualmente, el Mari Carmen constituye, a fin de cuentas, una grata sorpresa. Carmen Casas

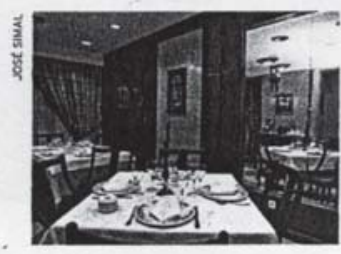

OIReccion Carretera nacional $122, \mathrm{~km}$ 113. Matalebreras (Soria)/ DiA DE CIERRE NingunO / PRECIO APROXIMADO POR PERSONA 30 euros. Menú: 9,25+IVA/ JEFE oE cocina Javier Garcia / Jefes oe SALA Y dirección Jesús Caba y Mari Carmen/ CALIFICACIÓN 10/20.

\section{Las" Cinco Calderas}

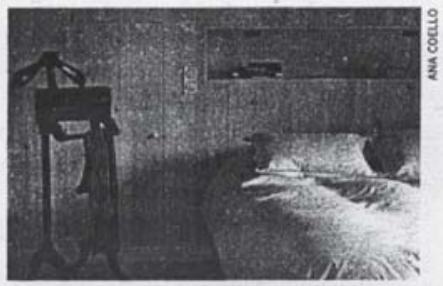

Galizano (Cantabria). Ofrece tranquilidad a la vez que facilidades para nirios. ¿cómo? Separando muy ciaramente los espacios y aportando soluciones para una convivencia armóniç. Para los niños, un jardín de $5.000 \mathrm{~m}^{2}$ con área de juegos, canguros y menú infantil. Para los adultos, bañeras de hidromasaje, biblioteca y un interiorismo cultural y esteta.

En esta casona montañesa conviven la viguería antigua, la sillería y la escalera de doble tramo con pavimentos de hormigón, lámparas de diserio, lavabos de barro contemporáneos y una colección de destacados pintores cántabros.

Maria Diez y Juan Manuel Ruiz, sus propietarios, no son amantes de los hoteles impersonales. Y ser diferentes les exige el esfuerzo de buscar cada elemento con cuidado. Del mismo modo, la cocina, siendo casera, no puede llevar solamente este adjetivo: es sencilla y liviana y nacida de la creatividad. Las habitaciones también son diferenciadas: las hay estándares, con galería acristalada, con salón y una suite espectacular con varias dependencias independientes. El estilo también varía, de las más rústicas a las más vanguardistas. Los airededores albergan playas estupendas, y a sólo 15 minutos se halla un paraje espectacular: la reserva natural de las Marismas de Santoña. En el hotel también se ofrecen facilidades para la práctica del turismo activo. Ana Coello

oirección Galizano. 39160 Cantabria. Tel:-942-505-089/ CatecoRia Tres estrellas/ instaL acioncs Nueve habitaciones dobles y especiales. Salón, biblioteca, comedor y sala de desayunos. Jardin y zona infantil. Aparcamiento/ Precios Doble: $58-82 €$, con desayuno.
VINO

\section{Castell del Remei 1780 D. O. COSTERS DEL SEGRE}

La zona leridana de costers del Segre ha mostrado de sobras su potencial para los tintos muy expresivos y de alto octanaje por su ambición de perdurabilidad. El acentuado clima y la buena adaptación mostrada por diversas variedades foráneas facilitan la elaboración de vinos de gran personalidad, bien estructurados, potentes sin ser agresivos, muy aptos para la crianza y la guarda.

Castell del Remei documenta su primera vendimia histórica en 1780 y con ella etiqueta un vino que, sin embargo, es muy moderno, no sólo por su acertada combinación de tempranillo con cabernet sauvignon y garnacha, sino también por su perfil organoléptico.

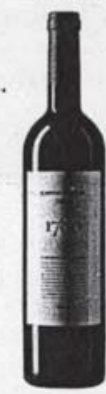

La añada del 2000 de Castell del Remei muestra un bello color de cereza picota, oscuro y con ribete morado, aromas potentes, maduros $y$ confitados, con interesantes apuntes minerales y paladar bien ensamblado, firme, sabroso y con buena persistencia. Aifred Rexach

ripo Tinto crianza. 13\%. / CALIFICA. CiON 16/20. 
El titular de estas críticas recoge únicamente la marca valorada, sin ningún otro tipo de elemento. Debajo del mismo se incluye la denominación de origen a la que pertenece. Otros datos, tales como el precio, el nombre de la bodega (que no siempre coincide con el de la marca), o los varietales empleados en la elaboración no aparecen destacados, si bien estos últimos suelen aparecer recogidos dentro del texto.

A lo largo de 2003, el Magazine publicó 22 críticas, ya que no siempre el apartado vinícola acudió a su cita del fin de semana. Así, no se publicó ninguna crítica durante los meses de enero y agosto. Apareció 1 en noviembre, 2 en febrero, marzo, junio, septiembre, octubre y diciembre; y 3 en abril, mayo y julio. Descartando agosto, por su carácter vacacional; cabe afirmar que aproximadamente en la mitad de los fines de semana de 2003 la crítica enológica del Magazine acudió a su cita con los lectores.

El crítico de Magazine es Alfred Rexach, autor de obras como Vins i cabes de Catalunya (Edicions lisard, Barcelona, 2000) o Guía de vinos, 1997 (Columna edicions, Barcelona, 1997). Sus textos carecen de una ficha técnica en sentido estricto diferenciada del cuerpo de la reseña, si bien al final de la misma se especifica el tipo de vino analizado (tinto, blanco, etc.), la graduación y la calificación (sobre un global de 20 puntos).

Las críticas de Alfred Rexach suelen constar de unas 150 palabras (unos 8001000 caracteres), lo que da idea de su brevedad. El primer párrafo se utiliza a modo de introducción para desgranar una serie de ideas generales sobre el tipo de vino elegido o sobre la zona de producción del vino; mientras que la segunda mitad del texto se dedica a la valoración en sí.

\subsection{El objeto de estudio: DOs y tipos de vino}

Entre las Denominaciones de Origen elegidas por Alfred Rexach para su análisis destaca el Rioja (4 vinos), seguida del Penedés (3) y de Ribera del Duero, Priorat y Navarra, con 2 marcas cada una. Rexach analizó a lo largo de 2003 un caldo de las denominaciones Campo de Borja, Conca de Barberá, Málaga, Montsant, Rueda, Somontano, Terra Alta y Toro. Al margen de las DO citadas, fue reseñado el Mauro Vendimia Seleccionada 98, catalogado como Vino de la Tierra.

Aunque, al igual que sucedía en El Semanal, Rioja fue la DO más citada; en números absolutos cabe hablar de un mayor equilibrio entre las distintas regiones vinícolas. Así, por ejemplo, se incluyeron dos vinos del Priorat, mientras que esta DOC no mereció a lo largo de 2003 crítica alguna por parte de las otras dos publicaciones ya estudiadas. Otro tanto puede decirse de zonas como Conca de Barberá o Terra Alta. En total, el número de DOs mencionadas alcanzó las 13.

En lo que a puntuación alcanzada se refiere (sobre un total de 20), la clasificación en sus diez primeros puestos quedaría de la siguiente manera (como ya hemos señalado, en las críticas de Magazine no aparece el precio de las botellas): 
112 La selección temática de la crítica de vinos en la prensa española

Con 18 puntos:

- La Vicalanda. Tinto Gran Reserva 1996. Bodegas Bilbaínas (DOC Rioja).

- Molino Real 99. Blanco dulce. Compañía de Vinos de Telmo Rodríguez (DO Málaga).

Con 17 puntos:

- Colet 2001. Blanco. Bodega Colet (DO Penedés).

- Chivite 2000 Colección 125. Blanco. Bodegas Julián Chivite (DO Navarra).

- Finca Els Camps "Ull de llebre 2001". Tinto crianza. Bodega Jané Ventura (DO Penedés).

- Mistela Josefina Piñol 2001. Mistela de tinto. Bodega Celler Vinos Piñol (DO Terra Alta).

- Mauro Vendimia Seleccionada 98. Tinto crianza. Bodegas Mauro (Vinos de la Tierra de Castilla y León).

- Barranc dels Closos 2002. Blanco. Bodega Mas Igneus (DOC Priorat).

- Numanthia 2000. Tinto. Bodegas Vea de Toro (DO Toro).

- Faustino de autor 1995. Tinto reserva. Bodegas Faustino (DOC Rioja).

Como puede verse, en estos diez vinos más puntuados sólamente se repiten dos zonas (Penedés y Rioja). La puntuación media alcanzada por los vinos analizados por Alfred Rexach fue de 16,4 puntos.

Por lo que respecta a las Comunidades Autónomas a las que pertenecen los vinos citados en las críticas, Catalunya figura en primer lugar con 8 menciones. Curiosamente, es en esta comunidad donde está ubicado el Grupo Godó, uno de los coeditores del suplemento. En segundo lugar figura Castilla y León (5 vinos), en donde se venden diarios como La Razón, La Opinión de Zamora y El Adelantado, que también distribuyen el Magazine. Con 2 representantes estarían comunidades como La Rioja, Aragón, País Vasco (si bien pertenecientes a la DOC Rioja) y Navarra. Por último se situaría Andalucía con un único vino analizado.

En cuanto al tipo de vino analizado en estas críticas, cabe destacar que también en este caso los tintos ocupan un lugar predominante (en 14 de los 22 textos estudiados), 5 comentarios se refirieron a blancos y 3 a vinos dulces (una mistela, un málaga y un penedés).

En cuanto a la edad de los vinos, el bloque principal (15 casos) lo ocupan los caldos sin etiquetado de crianza. Ello no significa necesariamente que en todos los casos se trate de vinos jóvenes o de que no hayan pasado por barricas de roble. Lo que ocurre es que en sus etiquetas no aparece especificado el término crianza o reserva. Magazine incluyó en sus análisis 3 caldos de crianza, 2 reservas y otros 2 gran reserva. 


\section{Magazine: DO analizadas en 2003}

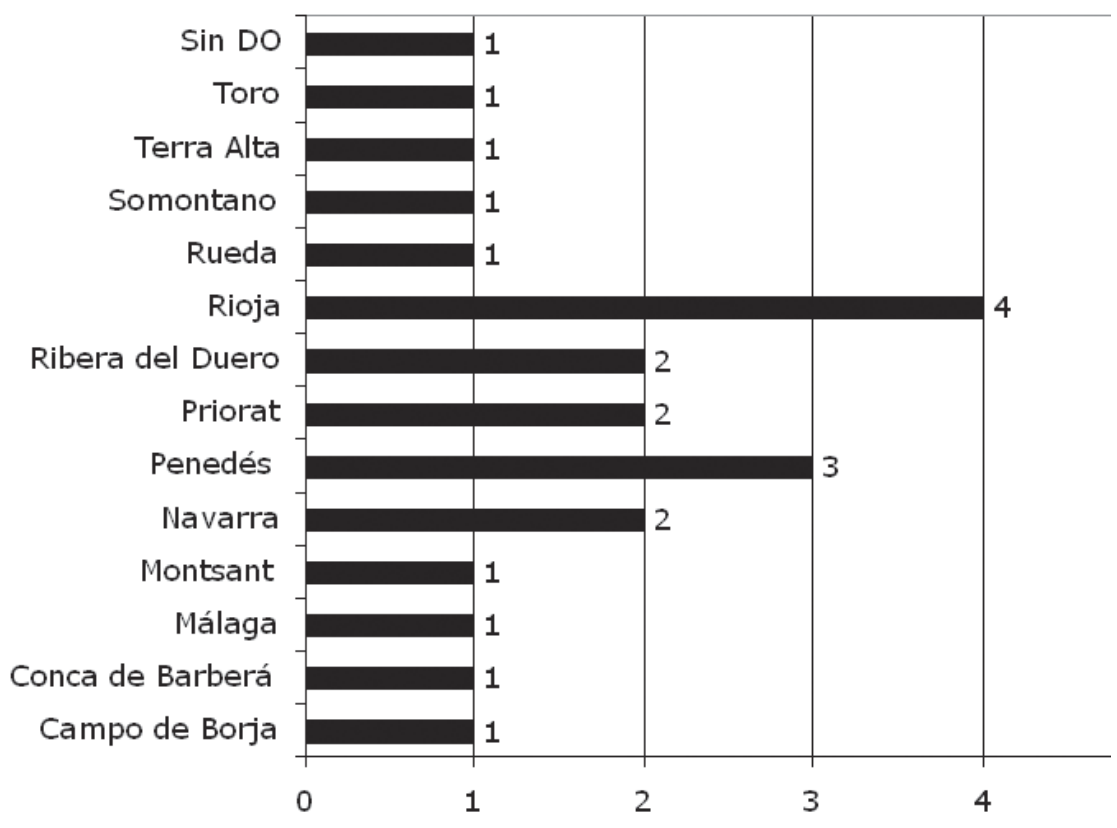

Magazine: Presencia de las distintas DO en 2003 (\%

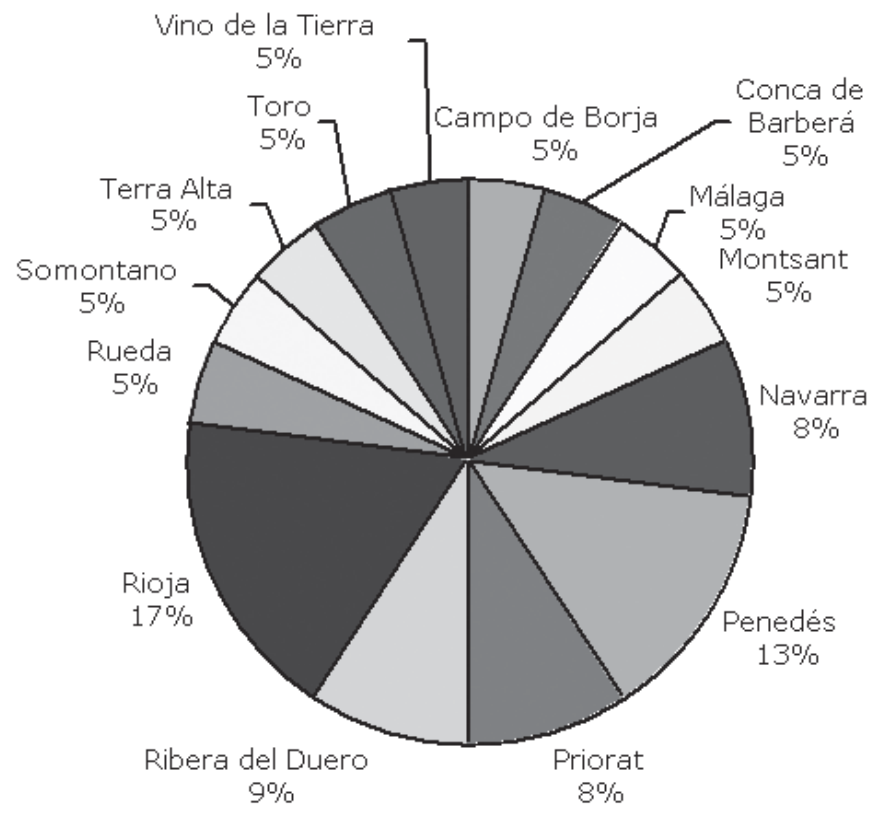


114 La selección temática de la crítica de vinos en la prensa española

\section{$N^{\circ}$ de vinos criticados por Autonomía:}

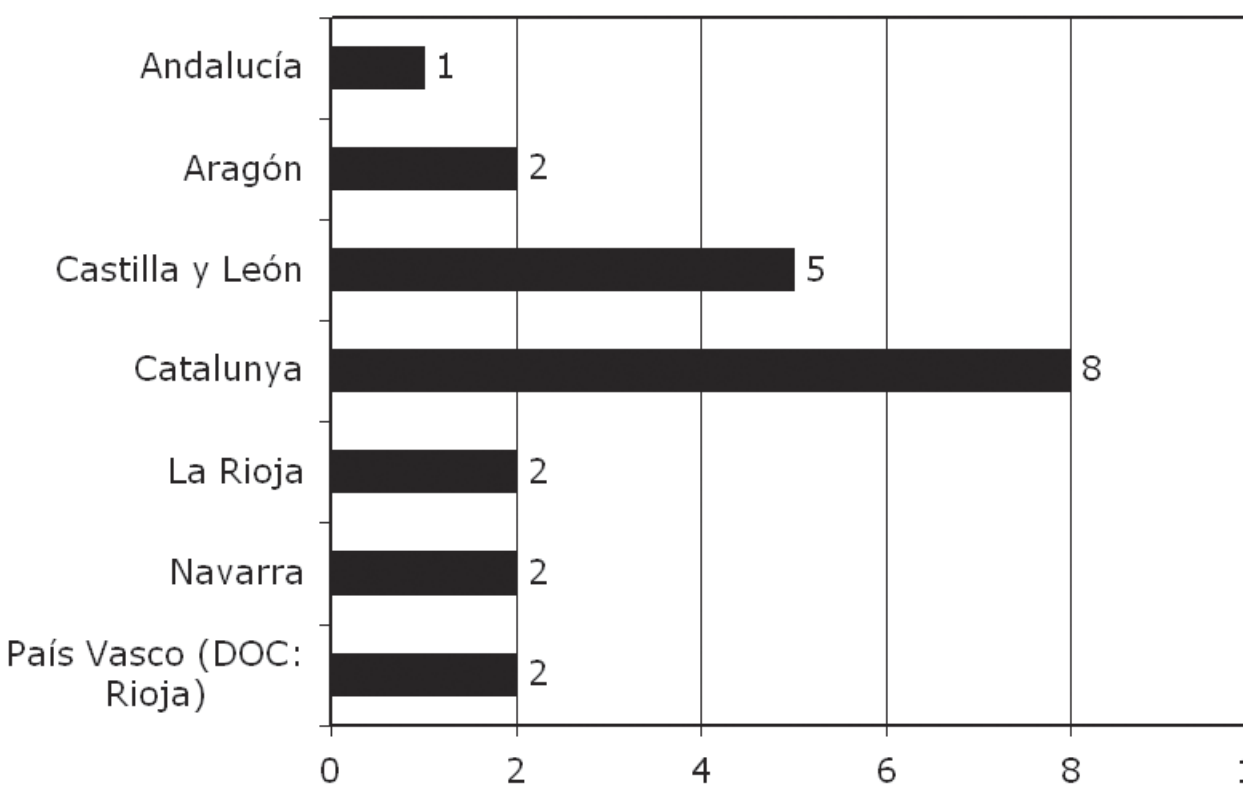

No de vinos criticados por Autonomías (\%)

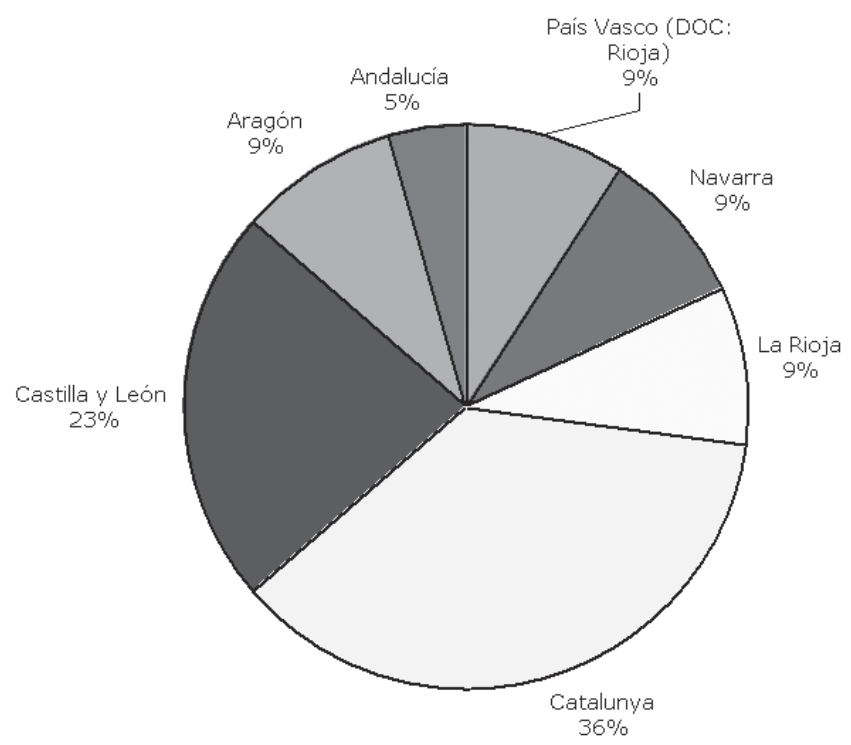




\section{Tipo de vinos}

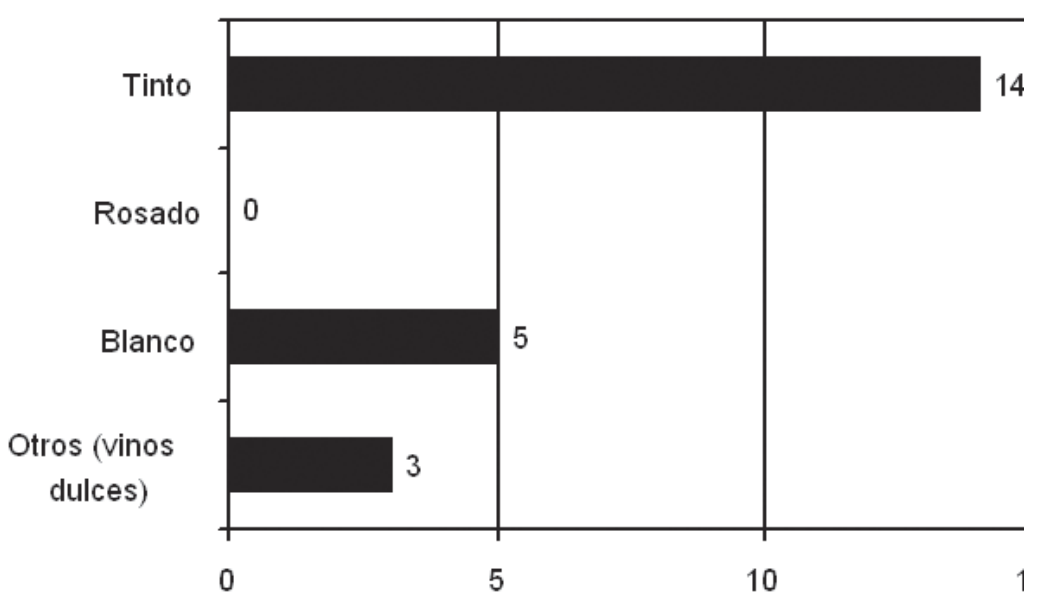

\section{Tipo de vinos}

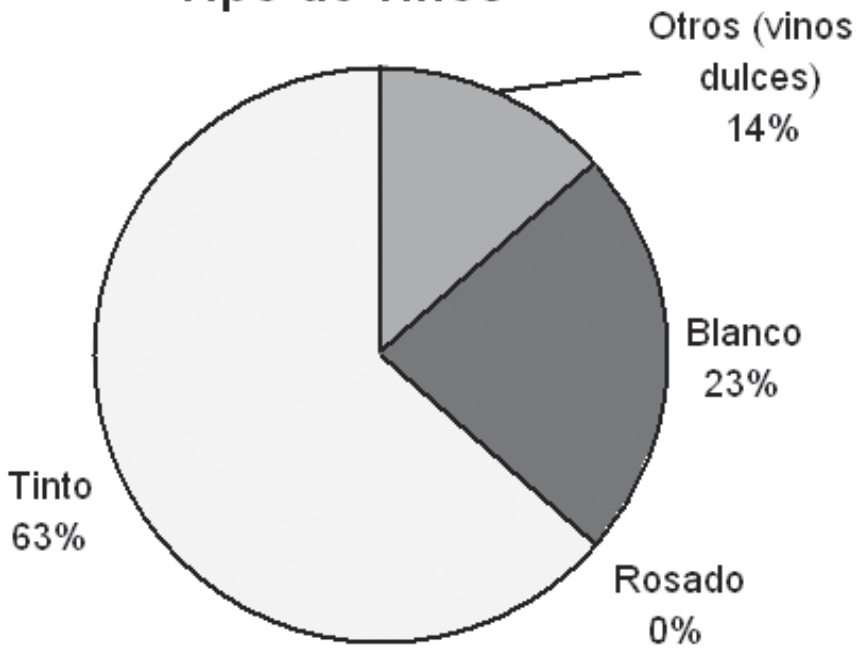


116 La selección temática de la crítica de vinos en la prensa española

\section{Edad de los vinos}

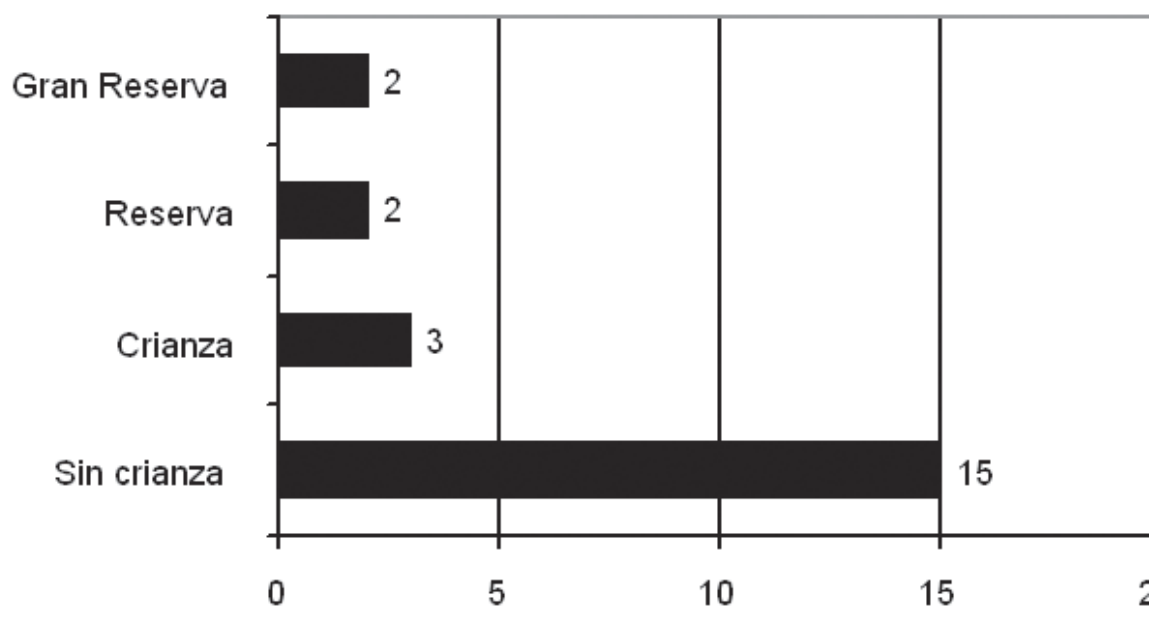

\section{Edad de los vinos}

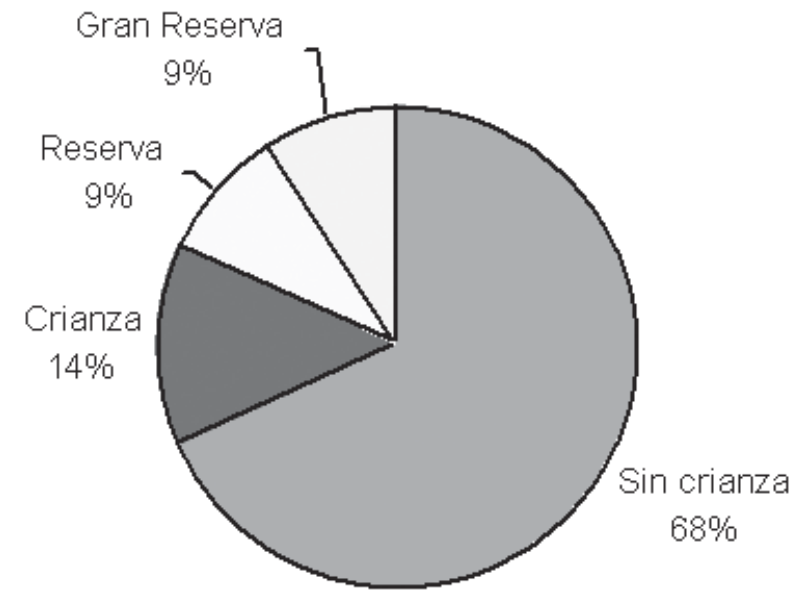




\section{SUPLEMENTO DOMINICAL}

\subsection{Introducción}

Como ya se ha señalado en la introducción general, el suplemento arrevistado de fin de semana denominado Dominical nació en 2002 merced a una iniciativa conjunta de los grupos Prisa y Zeta. Durante 2003 esta publicación alcanzó por término medio una difusión de 346.575 ejemplares.

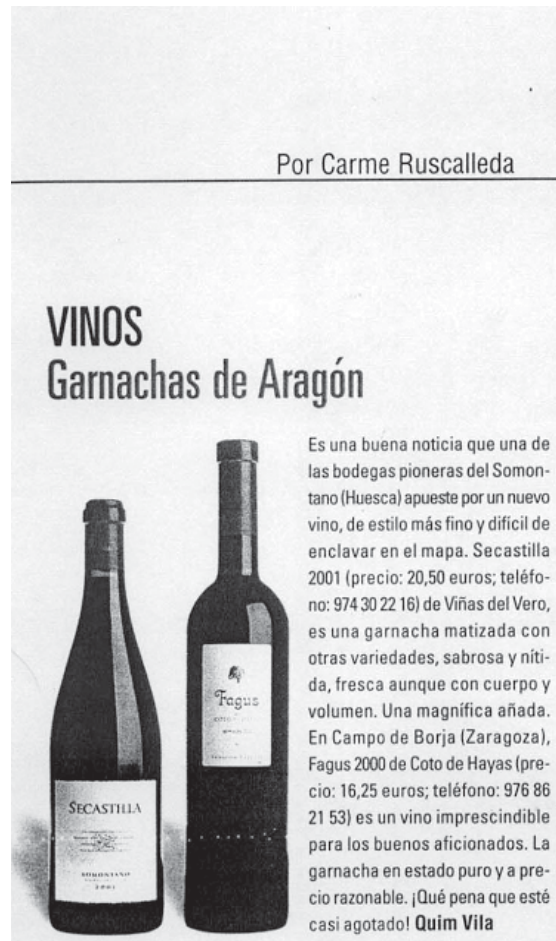

EL MERCADO Planta calmante

El romero era conocido antiguamente con el nombre de príncipe de los aromasy rosa del mar. Esta planta, de hojas finas y estrechas, es de color verde grisáceo y tiene pequeñas flores. El romero, que crece en toda la cuenca mediterránea, se reconoce por un aroma fuerte, algo picante y amargo. Sus hojas se usan en perfumeria y en farmacia por sus propiedades antisépticas, calmantes y anties pasmódicas. Por su intenso perfume debe utilizarse con moderación. Guillermina Botaya

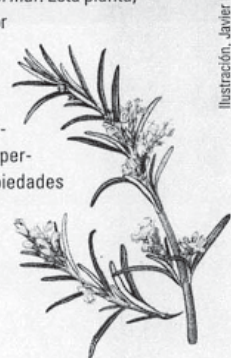

Sacha

OÍDO COCINA

\section{La cocina del mañana}

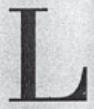

a perfección también se busca en la cocina. Los profesionales están cada vez más interesados en las nuevas técnicas, pero esto no significa que desdeñen las maneras de siempre, las de la cocina llamada tradicional. Es incoherente el cocinero que pretende usar el sifón para hacer una espuma de patata sin saber cocerlas ni usar un pasapurés. Si observan bien, esos grandes chefs de hoy valoran y conocen tanto la cocina de siempre como las técnicas recién llegadas. Por eso, cae en un grave error quien ve un enemigo en las nuevas maneras de cocinar. Alguien piensa que si la batidora tuviera 200 años, las amas de casa del pasado quizá no la habrian usado, pero los recetarios de cocina clásica estarian llenos de referencias a este utensilio.

El futuro ya está aquí y se llama cocina al vacío, que no se debe confundir con esa técnica de envasado para conservar los alimentos. Esta nueva aportación de la tecnología a los fogones consiste en cocinar los productos envasados al vacío y así conseguir mejorar sus texturas, olores, sabores... Este proceso, además, sirve para todas las cocinas, desde las que tienen un corte de tradición hasta las consideradas de vanguardia. Lo mismo sucede con los restaurantes: igual le aporta ayuda a uno de 10 mesas que al banquete de 500 personas. Se puede preparar un plato en un horno de vapor o en una olla de agua hirviendo, pero mejor en la roner, última novedad: se trata de un baño María en el que se controla exactamente la temperatura del agua. Y todo esto para que los puntos̉ de cocción sean perfectos.

Las nuevas técnicas evitan que se resequen los productos y que pierdan humedad. De paso, los jugos y aromas no desaparecen. Un ejemplo: ¿Se imaginan un redondo de ternera asado poco a poco, a baja temperatura, con sus verduras en un envase para que no pierda nada de sustancia y que además esté preparado por usted? Pues, si quiere aprender, hay libros y páginas en la Red que le ayudan, además de algunos cursos como los que organiza en toda la Península la revista Cocina futuro. Sólo hay que conectarse con bcarrera@cocinafuturo.com para comenzar a soñar con la cocina del mañana.

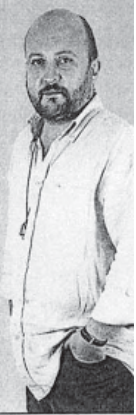


118 La selección temática de la crítica de vinos en la prensa española

Durante el citado año fue distribuida por los periódicos de la cadena Zeta ( $E$ I Periódico de Catalunya, Mediterráneo, Ciudad de Alcoy, El Periódico de Aragón, La Voz de Asturias, El Periódico de Extremadura, Córdoba, El Adelanto), y los rotativos locales asociados a Prisa (Odiel Información, El Correo de Andalucía, Jaén, La Voz de Almería, El Día de Valladolid), así como por otros periódicos ajenos a dichos grupos pero que han alcanzado un acuerdo para el reparto de Dominical (Alerta, Área, Deia, Diario de Noticias, Diario de Pontevedra, Diario de Soria, Diario de Teruel, Diario Palentino, El Periódico de Álava, El Progreso, La Prensa de Zamora, La Tribuna de Albacete y Lanza).

Este suplemento cuenta con una sección fija destinada a la gastronomía, en la que incluyen sus textos diversos colaboradores. El apartado dedicado al vino está a cargo de Quim Vila, elaborador, distribuidor de distintas bodegas españolas, importador y promotor de diversos eventos de divulgación de la cultura del vino, como cursos y catas, amén de director de las tiendas especializadas "Vila Viniteca".

Los textos de Quim Vila están mucho más cerca de la reseña, entendida como un texto sucinto, pero claramente valorativo, que de la crítica opinativa. Se trata de piezas muy breves (unas 45 palabras, 220 caracteres), que carecen de ficha técnica. Tampoco existe una puntuación del producto, como hemos visto en otros críticos. Sí aparecen siempre datos como el precio de la botella o el teléfono de la bodega. Asimismo, siempre cuenta con la presencia de una escueta valoración de no más de cuatro líneas "¡Qué sutil! ¡Qué rico! Es un sensual champaña para dejarse enamorar". (...) apunta hacia un blanco más fresco y perfumado que seduce desde su juventud. Por otro lado, el titular es apelativo ("Siguiendo el Duero") o incluso expresivo ("Para un momento especial"). Por todas estas consideraciones, podemos afirmar que estos textos son reseñas valorativas y opinativas, ya que la opinión del autor aparece reflejada tanto en el titular como en la descripción de los caldos.

Una de las características de los textos de Quim Vila es que siempre se refieren a dos vinos diferentes. Generalmente, existe una relación entre las dos marcas elegidas (misma zona, mismo tipo de vino, misma variedad de uva,etc...); aunque, en ocasiones, esta relación no siempre resulta tan evidente y pueden compartir sección un rosado merlot del Penedés con un blanco Chardonnay navarro. A lo largo de 2003, Dominical publicó un total de 46 textos del citado autor.

\subsection{El objeto de estudio: DOs y tipos de vino}

Por lo que respecta a las Denominaciones de Origen elegidas por el Dominical, no puede sorprender el gran número de zonas vinícolas recogidas en el mismo, habida cuenta de que cada semana se mencionaban dos marcas distintas, pertenecientes, en muchas ocasiones a regiones diferentes. Así, aparecen citadas un total de 24 Denominaciones de Origen españolas, a las que habría que añadir los llamados Vinos de la Tierra ( 3 zonas mencionadas: Montes de Toledo, Baleares y Castilla y León). Asimismo, aparece un Vino de Pago y una serie de marcas (12 
en total) correspondientes a otros países (Francia, Alemania, Nueva Zelanda y Portugal). En total, fueron 92 las botellas reseñadas por Quim Vila.

Ribera del Duero es la DO que más veces (11) aparece citada, seguida por Rioja y Priorat (7 cada una). Por Comunidades Autónomas, dos son claramente los territorios cuyos vinos fueron reseñados en más ocasiones: Catalunya (26 citas) y Castilla y León (22). A una gran distancia se encontrarían Navarra y Comunidad Valenciana con 5 marcas, y La Rioja con 4. En total, son 12 las comunidades mencionadas en la sección gastronómica del Dominical. Al igual que sucede en los otros suplementos estudiados, cabe establecerse una relación de cercanía entre la ubicación del diario-cabecera en la distribución de este tipo de publicaciones (en este caso El Periódico de Catalunya) y la zona geográfica que se ve favorecida en cuanto a número de menciones.

Respecto al tipo de vinos, y al igual que sucede en otras publicaciones, son los vinos tintos los que aparecen mayormente citados. Casi las 2-3 partes de los caldos reseñados (un $65 \%$ ) son tintos. A una considerable distancia $(24 \%)$ se encuentran los blancos, los espumosos (8\%) y los rosados (3\%).

Por lo que se refiere a la edad de los vinos analizados, destacan aquellos en cuya etiqueta no se especifica una denominación de crianza o reserva $(78 \%)$. Ello, claro está, no significa necesariamente que se trate de vinos jóvenes. Muchos de ellos han sido sometidos a un envejecimiento más o menos prolongado en barricas. Lo que ocurre es que, bien porque no cumplen los criterios de la DO correspondiente para ser considerados crianzas, o bien porque se trata de marcas más o menos consolidadas que no recurren a este tipo de nomenclatura, el etiquetado no especifica el calificativo de crianza, reserva o gran reserva. Ello no quita el que hayan pasado algún tiempo en barricas de roble.

Aunque Quim Vila no puntúa los vinos a los que alude en sus textos, sí que ofrece al lector el precio de los mismos. A lo largo de 2003 el precio medio de las botellas analizadas se situó en 24,37 euros. 
120 La selección temática de la crítica de vinos en la prensa española

Dominical: Do analizadas en 2003

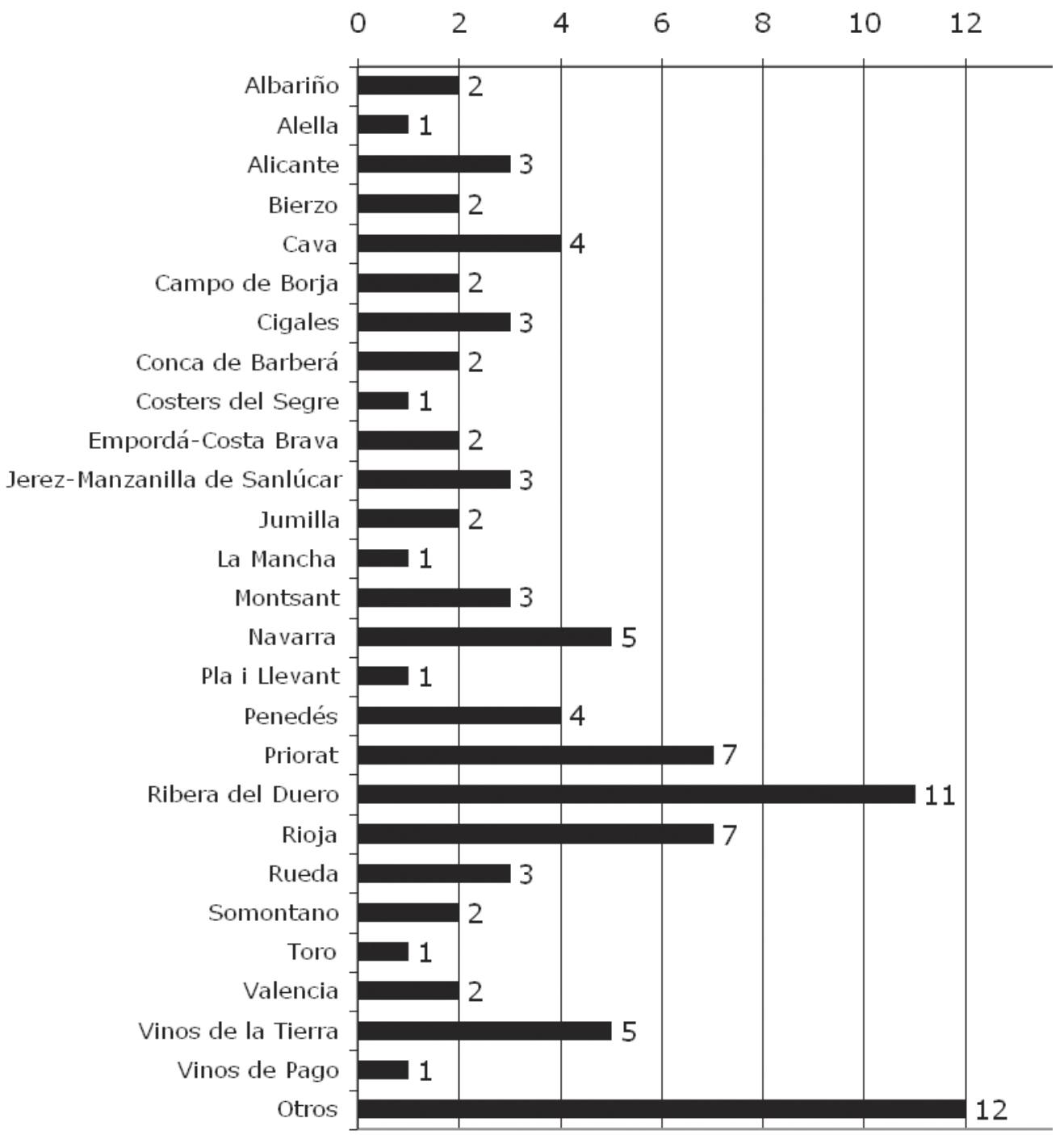




\section{Dominical: DO analizadas en 2003 (\%)}

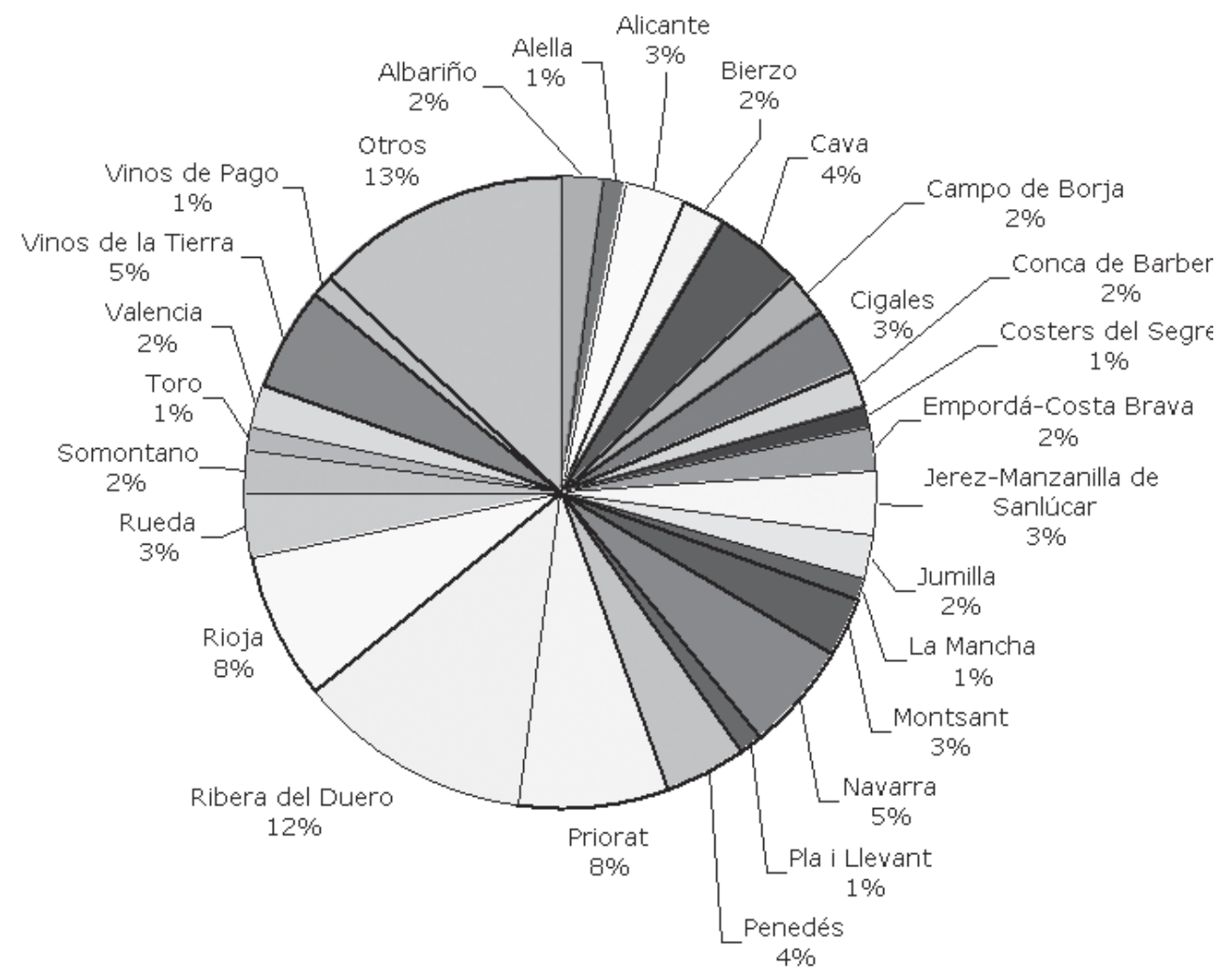




\section{No de vinos citados por Autonomías}

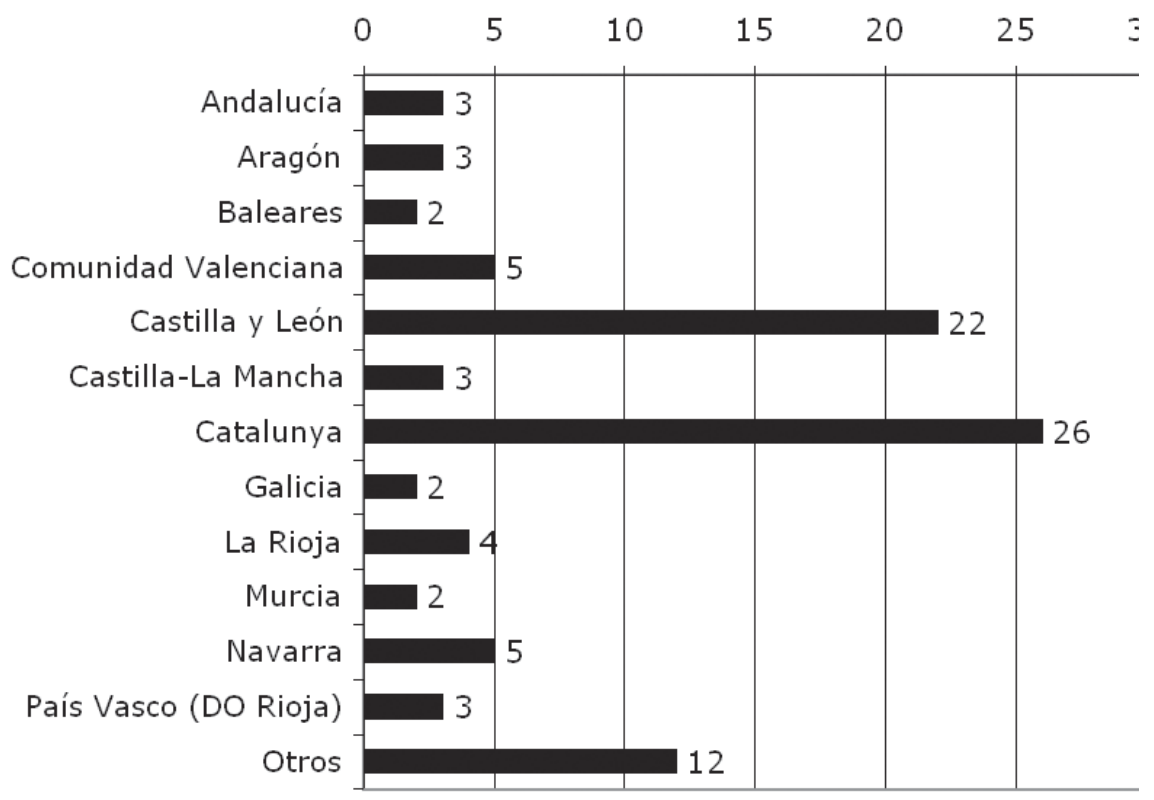

\section{No de vinos citados por Autonomías (\%)}

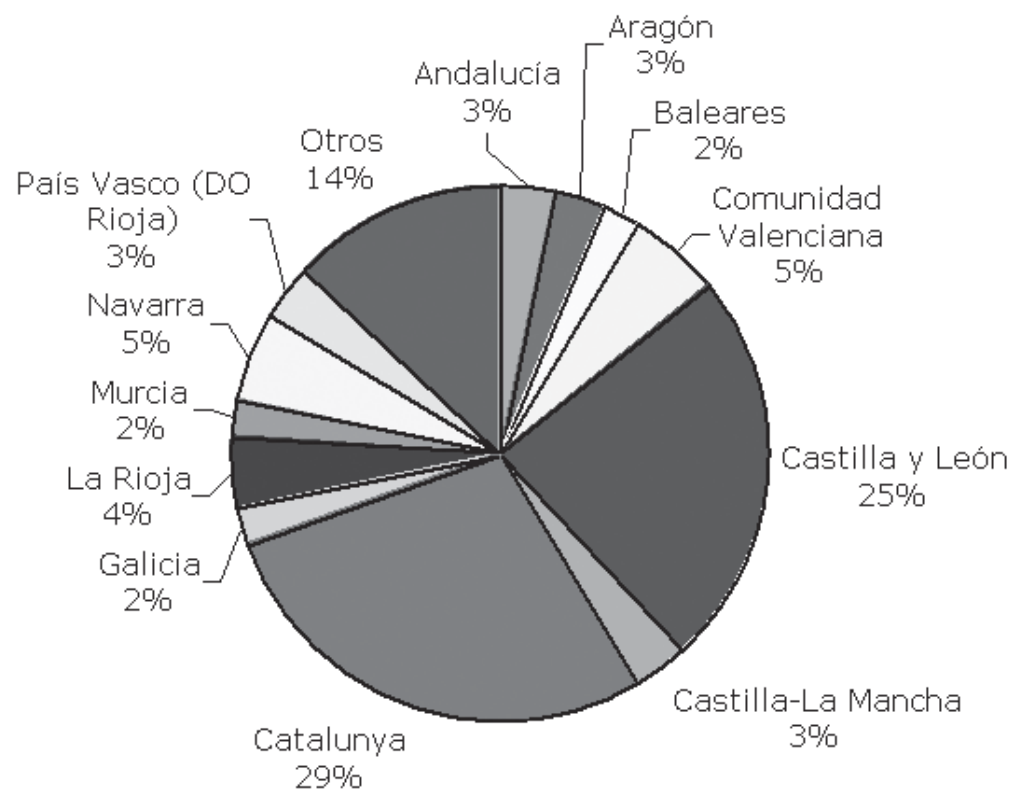


Tipo de vinos criticados

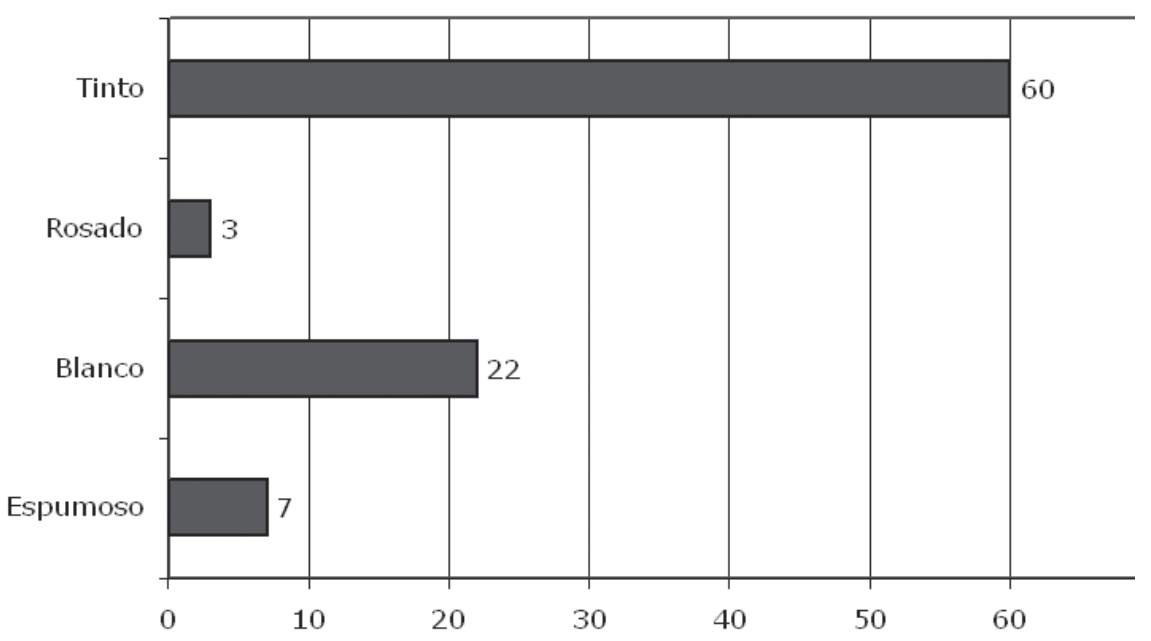

\section{Vejez de los vinos criticados}

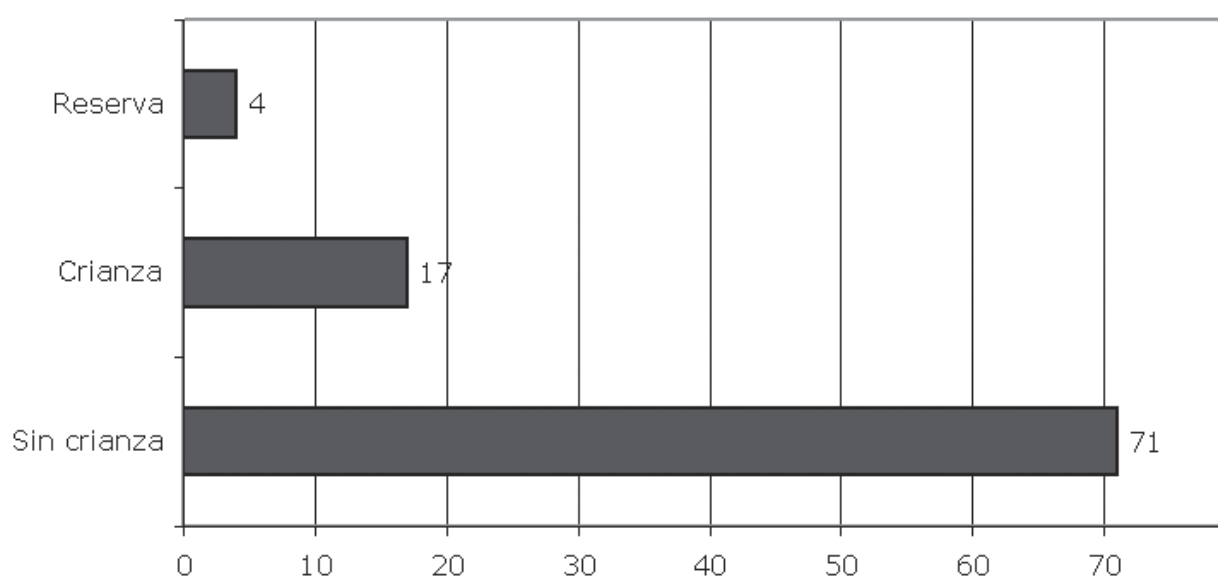


124 La selección temática de la crítica de vinos en la prensa española

\section{Tipo de vinos criticados (\%)}

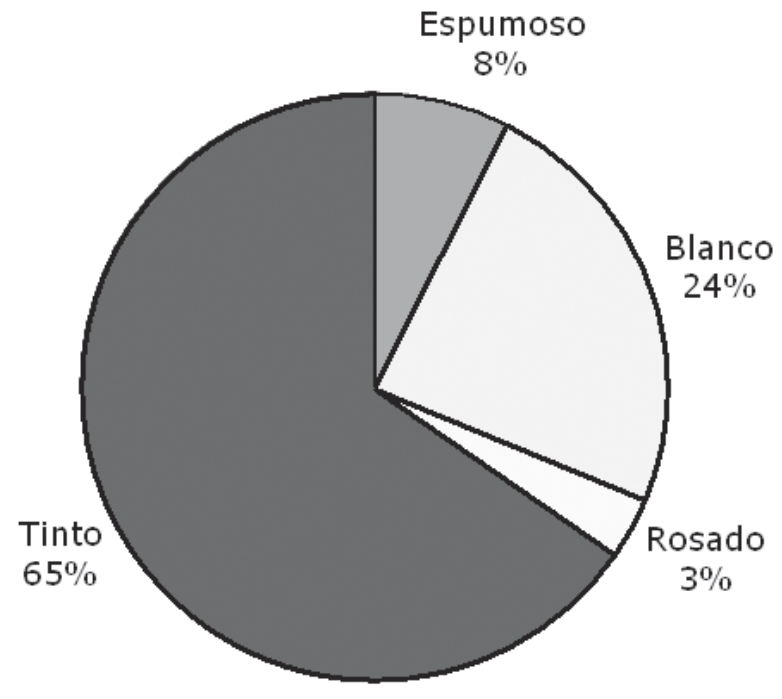

\section{Edad de los vinos (\%)}

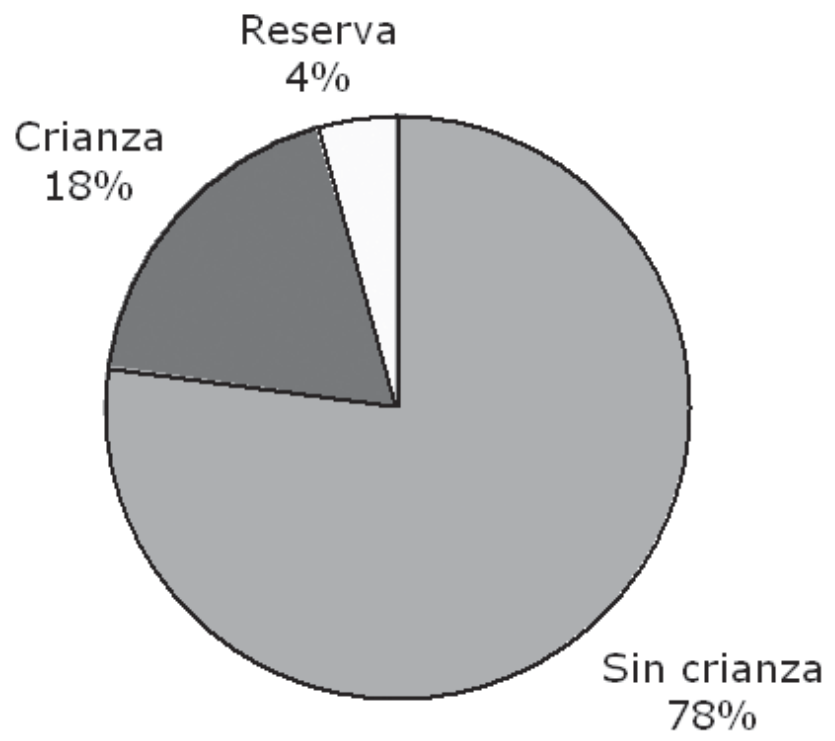




\section{CONCLUSIONES}

Durante el 2003, los principales diarios españoles utilizaron distintos suplementos para ubicar la sección de crítica enológica. En el caso de El País los textos fueron publicados en el cuadernillo temático El Viajero, que se reparte embuchado los sábados en el interior de la publicación. Rotativos como ABC, La Vanguardia, El Periódico, El Correo y otros han delegado esta sección en los suplementos arrrevistados de fin de semana. En estos casos, se trata de suplementos compartidos por una o varias cadenas de periódicos. Así, los diarios del grupo Vocento (junto a otros como Heraldo de Aragón, La Voz de Galicia, etc.) distribuyen El Semanal. La Vanguardia, La Razón y el Grupo Prensa Ibérica ofrecen Magazine. Por último, el Grupo Zeta, los diarios locales ligados a Prisa, más otras publicaciones regionales (Deia, Diario de Noticias, etc.) reparte el Domincal.

Es decir, se puede afirmar que hoy por hoy la crítica enológica todavía no ha llegado a las secciones diarias de los periódicos y todavía queda restringida a las páginas de servicios de los suplementos de fin de semana; normalmente, junto a textos dedicados a los viajes o a la gastronomía.

La morfología de los textos dedicados al vino tampoco es homogénea. En algunos casos responden claramente al modelo de crítica de consumo. Este es el caso de la sección "Beber", responsabilidad de Carlos Delgado y publicada por el suplemento temático El Viajero (dedicado, como su nombre indica, a viajes, gastronomía y motor). En este caso nos encontramos con un titular generalmente apelativo o expresivo, una ficha técnica, en la que se incluye una valoración sobre 10 puntos, y un par de párrafos. En el primero de los cuales se nos describen las características generales de la marca y bodega elegidas, mientras que en el segundo se realiza un análisis gustativo-aromático del caldo seleccionado.

Muchísimo más breves son los textos firmados por Juan Luis Recio en El Semanal del grupo Correo y que se suelen ubicar bajo las recetas del reputado cocinero Martín Berasategui. El titular contiene únicamente el nombre del vino elegido y de las 8 líneas de que suele constar el comentario, 2 ó 3 van dedicadas a una descripción aromática y gustativa de dicho caldo. A modo de conclusión, se ofrece siempre el precio aproximado de la botella. El tipo de texto lo encuadraríamos en la reseña valorativa.

Las críticas de Alfred Rexach para el Magazine podrían situarse a medio camino entre los dos ejemplos anteriores: ni tan detalladas como las de El Viajero, ni tan lacónicas como las de El Semanal. También en este caso el titular hace únicamente mención al nombre del vino analizado. Aunque no existe una ficha técnica propiamente dicha, tanto la Denominación de Origen, como el tipo de vino y la calificación que obtiene desde el punto de vista del crítico (sobre 20 puntos) aparecen diferenciados tipográficamente del resto del texto. La estructura de éste responde habitualmente a un esquema de tres párrafos. El primero de los mismos hace generalmente referencia a la DO, el segundo a la bodega en sí y el último a las características organolépticas del caldo analizado. 
Por último, las colaboraciones de Quim Vila para el Dominical estarían más cercanas de la reseña valorativa que de la crítica propiamente dicha. Al igual que en el caso de El Semanal, nos encontramos con textos muy breves, explicativos y valorativos y que normalmente hacen mención a dos marcas distintas, incluso de DOs diferentes. También en este caso se destaca el precio de cada botella.

Por lo que respecta a las zonas mayoritariamente analizadas, sí que, en cierta medida, se observa una cierta relación entre la región en la que se ubica la empresa propietaria (o principal accionista) de la publicación y las DOs mayoritariamente seleccionadas en las críticas. Así, El Viajero de El País se inclina, en el periodo analizado, mayoritariamente por los vinos castellanos y de Madrid: un $47 \%$ del total. El contrapunto lo pone nuevamente la publicación de Vocento-Grupo Correo El Semanal: Ios vinos del País Vasco, la Rioja y Navarra acaparan el $46 \%$ de las reseñas. En el Magazine del Grupo Godó y Prensa Ibérica también se trasluce, aunque más atenuada, esta tendencia. El $36 \%$ de los vinos citados son catalanes (como la editora Godó). Cataluña es, con un $29 \%$, también la región preferente en la publicación del grupo Zeta Dominical.

Aunque en todos los casos existe un claro predominio de los tintos frente a los restantes tipos de vino, también aquí existen claras diferencias porcentuales entre El Viajero (84\% de tintos), El Semanal (70\%), Dominical (65\%) y Magazine (63\%).

Por lo que se refiere al precio medio de los vinos mencionados en las críticas, en el caso de El Viajero éste se situó en 24,6 euros. Un coste similar $-24,37$ euros- se obtiene de los textos del Dominical. Considerablemente más económicos resultan los caldos incluidos en El Semanal: 14,79 euros. Cabe recordar que en las críticas de Magazine no se alude al precio de las botellas. Viendo estas cantidades, da la impresión de que la crítica enológica no se dirige a un público masivo, sino especializado y con un nada desdeñable nivel adquisitivo, o que al menos parece dispuesto a realizar ciertos desembolsos en la compra de este producto. En este sentido, cabe recordar que la marca que obtuvo una mayor puntuación en $E l$ Viajero a lo largo de 2003 -Artadi Viña El Pisón, TC-2000- tenía un precio de 95 euros; mientras que los dos caldos más valorados en el Magazine - La Vicalanda, TGR-1996 y Molino Real 99- alcanzaron un coste, respectivamente, de 46,5 y 29,9 euros. 


\section{BIBLIOGRAFÍA:}

ACADEMIA ESPAÑOLA DE GASTRONOMíA (2003): Guía CAMPSA. Los mejores vinos de España. RepsolYPF, Madrid.

AGUILERA, O. (1993): "La crítica, control de qualitat dels productes culturals. Composició dels textos periodístics", en Periodística, no6, pp. 106-109.

ARMENTIA, Alberdi, CAMINOS y Marín (2002): el diario de servicios en España. Septem, Oviedo.

CHILLÓN, Luis Albert (1993): Literatura y periodismo. Universidad de Alicante, Alicante.

FALCó, Carlos (2004): Entender de vino. MR ediciones, Madrid

GARAIZABAL, Mikel (2003): Euskal Herriko Ardoak. Vinos de Euskal Herria. Gobierno Vasco, Vitoria-Gasteiz.

GARCíA DEL Río, Fernando (2004): El método del catador. Guía práctica para entender el vino. Alianza, Madrid.

GUTIÉRREZ PALACIO, Juan (1994): Periodismo de opinión. Paraninfo, Madrid.

NÚÑEZ LADEVÉZE, Luis (1991): Manual para periodismo. Ariel, Barcelona.

PEÑín, José (2003): Guía Peñin de los vinos de España. Pi \& Erre Ediciones, Madrid.

PRoEnSA, Andrés (2003): Guía Proensa de los mejores vinos de España. Proensa, Madrid.

REARDON, K. (1983): La persuasión en la comunicación. Paidós, Barcelona.

SANTAMARÍA SUÁREZ, Luisa (1997): Géneros para la persuasión en periodismo. Fragua, Madrid.

SANTAMARÍA SUÁREZ, Luisa y CASALS CARRO, María Jesús (2000). La opinión periodística: Argumentos y géneros para la persuasión. Fragua, Madrid.

VALLEJO MEJíA, Mary Luz (1993): La crítica literaria como género periodístico. Eunsa, Pamplona.

WESTON, A. (1998): Las claves de la argumentación. Ariel, Barcelona.

(Recibido el 3-11-05, aceptado el 1-03-06) 